


\section{Transition support system approach for urban food security in the future}

The case of Ghana

Marijke Dijkshoorn-Dekker, Vincent Linderhof, Vasco Pinto, Wil Hennen, Diti Oudendag, Marijke Kuiper, Lindsay Shutes

This study was carried out by Wageningen Economic Research and was commissioned and financed by the Dutch Ministry of Agriculture, Nature and Food Quality within the context of the 'Metropolitan Solutions' research theme of the Knowledge Base (project number KB-25)

Wageningen Economic Research

Wageningen, June 2019

REPORT

2019-057a

ISBN 978-94-6343-960-2 
Marijke Dijkshoorn-Dekker, Vincent Linderhof, Vasco Pinto, Wil Hennen, Diti Oudendag, Marijke Kuiper, Lindsay Shutes, 2019. Transition support system approach for urban food security in the future; The case of Ghana. Wageningen, Wageningen Economic Research, Report 2019-057a. 44 pp.; 25 fig.; 7 tab.; 22 ref.

The population of the world is becoming increasingly urbanised due to a combination of natural population growth and rural-urban migration. This will pose major challenges to feed the future population and meet the Sustainable Development Goals. Meeting these complex challenges requires an integrated approach. The transition support system (TSS) approach integrates decision support tools and stakeholder analyses for these complex issues. This study has focused attention on the application of decision support tools of the TSS approach that visualises the urgency of future food security as a proof of concept. To this end, the future food security of the city of Accra, the capital of Ghana, has been taken as a case study. The use of Global-Detector and its maps illustrated a quick way to downscale data and projections from MAGNET (Modular Applied GeNeral Equilibrium Tool) and perform spatial analyses without the burden of acquiring additional data. Downscaling of macroeconomic results of future projections provides insights into future urban food security. Given these insights, stakeholders might urge policy or interventions. The results of the exercise are largely determined by the availability of data and maps; in particular, the more detailed information is available, the more accurate the results of our exercise will be.

Key words: Food security, Sustainable Development Goals, transition support system, Global Detector, MAGNET, urban, Ghana

This report can be downloaded for free at https://doi.org/10.18174/476203 or at www.wur.eu/economic-research (under Wageningen Economic Research publications).

(C) 2019 Wageningen Economic Research

P.O. Box 29703, 2502 LS The Hague, The Netherlands, T +31 (0)70 3358330 ,

E communications.ssg@wur.nl, http://www.wur.eu/economic-research. Wageningen Economic Research is part of Wageningen University \& Research.

\section{(cc) BY-NC}

This work is licensed under a Creative Commons Attribution-Non Commercial 4.0 International License.

(c) Wageningen Economic Research, part of Stichting Wageningen Research, 2019

The user may reproduce, distribute and share this work and make derivative works from it. Material by third parties which is used in the work and which are subject to intellectual property rights may not be used without prior permission from the relevant third party. The user must attribute the work by stating the name indicated by the author or licensor but may not do this in such a way as to create the impression that the author/licensor endorses the use of the work or the work of the user. The user may not use the work for commercial purposes.

Wageningen Economic Research accepts no liability for any damage resulting from the use of the results of this study or the application of the advice contained in it.

Wageningen Economic Research is ISO 9001:2008 certified.

Wageningen Economic Research Report 2019-057a | Project code 2282700373

Cover photo: vilax/Shutterstock.com 


\section{Contents}

$\begin{array}{ll}\text { Summary } & 5\end{array}$

1

$\begin{array}{ll}\text { Introduction } & 7\end{array}$

$\begin{array}{lll}1.1 & \text { Background } & 7\end{array}$

$\begin{array}{lll}1.2 & \text { Research question } & 8\end{array}$

$\begin{array}{lll}1.3 & \text { Structure of the report } & 8\end{array}$

$\begin{array}{ll}\text { Method for decision support tool } & 9\end{array}$

2.1 Economic model: MAGNET 9

2.2 Global-Detector $\quad 10$

$3 \quad$ Urban food security in Ghana under different scenarios

$\begin{array}{lll}3.1 & \text { Urbanisation and food security } & 11\end{array}$

3.2 The TSS approach to urban food security, Ghana 13

3.2.1 Future scenarios 13

3.2.2 Demographic developments 13

$\begin{array}{ll}3.2 .3 \text { Household clusters } & 14\end{array}$

$\begin{array}{ll}3.2 .4 & \text { Income per capita }\end{array}$

$\begin{array}{ll}3.2 .5 \text { Selection of food commodities } & 17\end{array}$

$4 \quad$ Mapping urban food security in Ghana $r$

$\begin{array}{lll}4.1 & \text { Food security in urban Ghana } & 18\end{array}$

4.1.1 Production and consumption $\quad 18$

$\begin{array}{ll}\text { 4.1.2 Per capita consumption } & 20\end{array}$

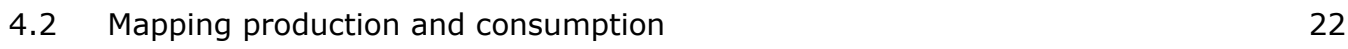

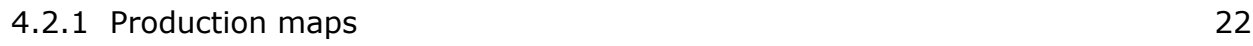

4.2.2 Consumption maps $\quad 27$

4.2.3 Supply and demand compared 28

4.2.4 Virtual production regions for urban consumption 29

$5 \quad$ Discussion and conclusions $\quad 35$

$\begin{array}{lll}5.1 & \text { Discussion } & 35\end{array}$

5.2 Conclusions $\quad 36$

References and websites $\quad 37$

Appendix 1 Global-Detector $\quad 39$

Appendix 2 Consumption of vegetables and fruit $\quad 42$

$\begin{array}{lll}\text { Appendix } 3 & \text { Consumption of paddy rice } & 43\end{array}$ 



\section{Summary}

The population of the world is becoming increasingly urbanised due to a combination of natural population growth and rural-urban migration. For Ghana, for instance, future population projections indicate that the share of urban population will increase from 54\% of the total population in 2015 to $70.4 \%$ in 2050 . This share for Ghana is considerable higher than that for western Africa (63.0\%) and for the African continent (55.9\%). Increased urbanisation will pose major challenges to feed the future population. Food security policies are typically targeted to agricultural development and rural population, but the poor households in urban areas in low-income countries may face even more severe challenges with respect to food security. Although there is often plentiful and diverse food present in the urban areas, it is far from being uniformly accessible to all citizens. Poor urban dwellers are largely net food buyers that depend on markets for their food supplies, thus being particularly vulnerable to food price shocks.

There is little empirical evidence, however, on urban food security and on how people living in urban areas will cope with sustained high food prices. Meeting this complex challenge requires an integrated approach to achieve and maintain sustainable development objectives, and to achieve improvements in global food security and nutrition. The transition support system (TSS) approach integrates decision support tools and stakeholder analyses for complex issues such as ensuring urban food security (Dijkshoorn-Dekker et al. 2017). This study focuses attention on the application of decision support tools of the TSS approach that visualises the urgency of future food security as a proof of concept. To this end, the future food security of the city of Accra, the capital of Ghana, has been taken as a case study.

\section{Conclusion}

This study demonstrates the application of the approach component related to the development of decision support tools of TSS. This is used to produce results that can be used as an input for discussion on future urban food security in Ghana, and the issue of self-support in the case of food supply to meet food demand in Accra and Kumasi (see the example for Accra in Figure S1). The use of Global-Detector and its maps illustrated a rather quick way to downscale data and projections from MAGNET (Modular Applied GeNeral Equilibrium Tool) and perform spatial analysis without the burden of acquiring additional data. Downscaling of macroeconomic results of future projections provides insights in future urban food security. Given these insights, stakeholders might urge policy or interventions. The results of the exercise are largely determined by the availability of data and maps; in particular, the more detailed information is available, the more accurate the results of our exercise will be.

\section{Approach and modelling framework}

To address the research objectives of this study, the TSS approach has been applied. TSS is an interactive approach based on the integration of existing decision support tools and dialogue approaches in an interactive process with the involvement of stakeholders. First, the advanced economic models are applied for estimating food production and consumption levels at the country level. Second, the outputs of these models are downscaled to geographic maps in order to illustrate differences in food consumption and production patterns across rural and metropolitan areas. Third, stakeholder contributions, in terms of judging on context-specific and scenario-oriented conditions, are incorporated in an iterative process. Hence, the key element of the TSS approach is that decision support approaches based on scientific research are combined with expert knowledge through stakeholder participation.

In this study, the participation process has not been initiated yet. The preliminary results obtained with the decision support tools, to visualise the urgency of future food security challenges in Ghana, are presented. In particular, the exploration of the future food security of the capital city of Accra, in regard to two types of food commodities: 1 ) vegetables and fruit (including nuts); 2 ) rice. The 
decision support tool of the TSS applied in this study consists of two elements: scenario analyses with the MAGNET global agro-economic model, and the Global-Detector GIS-based downscaling tool. First, MAGNET was used to give a general outline of changes that can be expected in food demand and land use for food production. These results were then downscaled with Global-Detector, in order to obtain the expected spatial patterns of food production and consumption within the territory of Ghana at a more refined spatial resolution $(2.5 \times 2.5 \mathrm{~km})$, resulting from the trends projected with MAGNET.

Three different scenarios were taken into consideration:

- SSP2: IPCC's Second Shared Socio-economic Pathways, which was considered as a reference 'middle of the road' scenario;

- ECO: Ecotopia, a scenario aiming at a sustainable and equal world;

- TLTL: Too little too late, a scenario aiming at economic growth i.e. inequality and an unsustainable world.

Vegetables, fruit and nuts

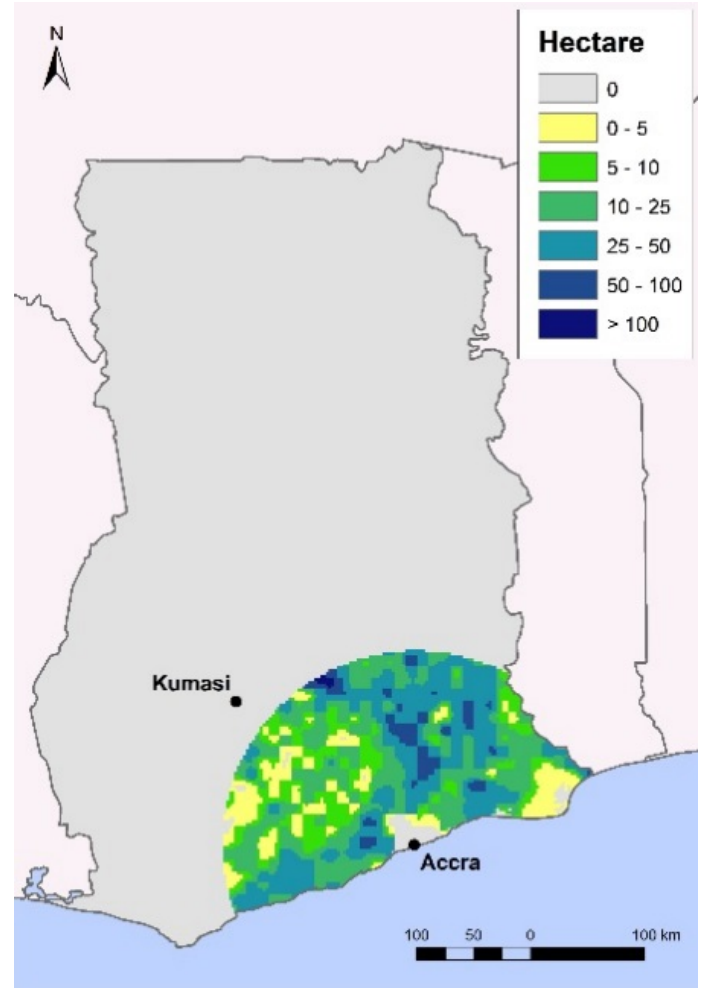

Rice

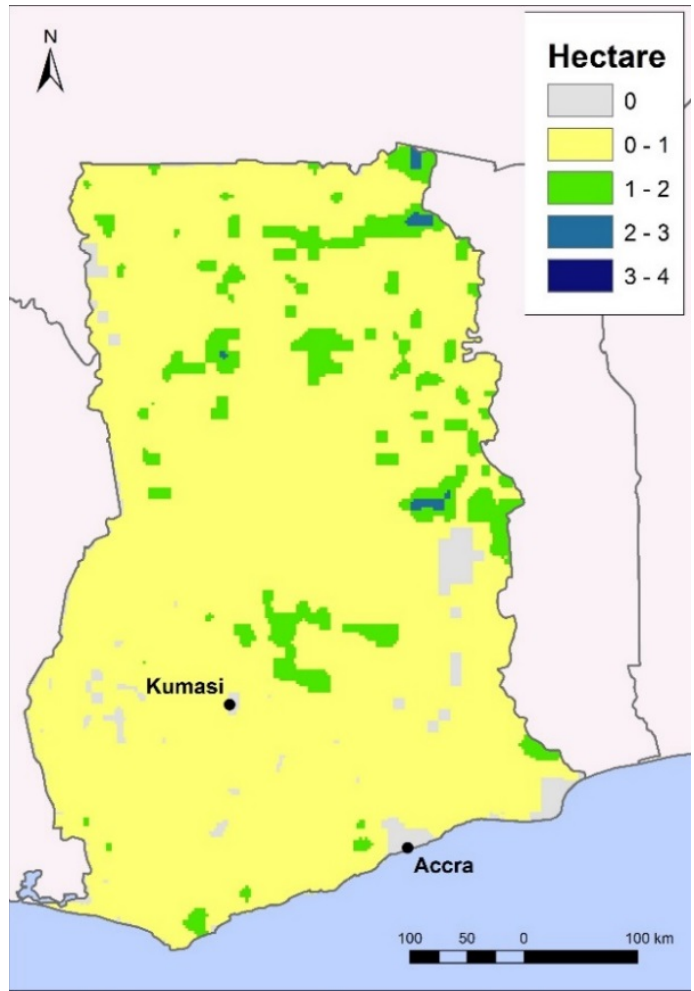

Figure S1 The area of virtual vegetable and fruit production (left) and rice production (right) for the urban centre of Accra for the ECO scenario in the period of 2030. It is assumed that supply equals demand in the production areas 


\section{Introduction}

\section{$1.1 \quad$ Background}

The growth and expansion of metropolitan regions is a global phenomenon. Today, $54 \%$ of the world's population (7.7 billion people) live in urban areas. By 2050, the proportion of the world's population (estimated at 9.8 billion people) is expected to rise to $68 \%$. Mega-cities with more than 10 million inhabitants are growing all over the world. In many countries, the relationship between urban and rural areas will change as a result of future urbanisation and climate change, with food security becoming a major challenge for urban centres. Meeting this complex challenge requires an integrated approach to achieve and maintain sustainable development objectives and to achieve improvements in global food security and nutrition.

The population of the world is becoming increasingly urbanised due to natural increase and ruralurban migration (Codjoe et al. 2016). There is a wide variety in the current share of urban population in the regions of the world (see Table 1 ). In Africa $40.4 \%$ of the population lives in urban areas, while in northern America the share is $81.6 \%$ (United Nations 2015). However, the projections for 2050 show a further increase in the share of urban population for all regions and it also shows there is a converging trend in the shares. The shares of urban population in Africa and Asia will increase the most (see Table 1).

Table 1 Share of urban population in the regions of the world, 1950, 2015 and the projection for 2050. Source: (United Nations 2015)

\begin{tabular}{llll} 
Regions of the world & 1950 & 2015 & $2050-$ projection \\
Africa & 14.0 & 40.4 & 55.9 \\
\hline Asia & 17.5 & 48.2 & 70.8 \\
\hline Oceania & 62.4 & 73.6 & 73.5 \\
\hline Europe & 51.5 & 79.8 & 82.0 \\
\hline Caribbean & 41.3 & 81.6 & 86.2 \\
\hline Northern America & 63.9 & 54.0 & 87.4 \\
\hline World & 29.6 & 66.4
\end{tabular}

The TSS is an interactive approach that is continuously based on the integration of different existing tools and dialogue approaches at Wageningen Economic Research (Dijkshoorn-Dekker et al. 2017). The TSS actually implies an interactive process with dialogues and discussions in which stakeholders are involved in multiple ways within and outside the scope of the particular research approach. This is a continuous process which contributes to different stages of transitions with small steps at a time. Eventually, the final state of the transition is reached. The TSS is suitable for complex problems and multiple transitions as is often observed in urban surroundings or metropolitan areas. First, the (Metropolitan) TSS has been developed to apply advanced models for food consumption across nations. Second, the outputs of these models have been transferred to place-based geographic maps to illustrate differences in food consumption across rural and metropolitan areas. Third, stakeholder contributions, in terms of judging on context-specific and scenario-oriented conditions, have been incorporated in the TSS. 


\section{Decision support: \\ a) Scenario analysis \\ b) Scaling tools \\ 2. Process support: Stakeholder participation tools}

\section{Monitoring and impact assessment}

Figure 1 Transition support system (TSS) approach (Dijkshoorn-Dekker et al. 2017)

The key element of the TSS approach is that decision support approaches based on scientific research is combined with expert knowledge through stakeholder participation (see Figure 1). The TSS approach explores transition pathways towards food and green secure (metropolitan) regions, so that key stakeholders can enhance their policies and transition strategies.

\subsection{Research question}

This study focuses attention on the use of decision support tools of the TSS approach that visualises the urgency of future food security as a proof of concept. To this end, the future food security of the city of Accra, the capital of Ghana, will be taken as a test case. We will present the approach and results for two food commodities. In this study, the participation process has not been initiated yet.

\subsection{Structure of the report}

Chapter 2 describes the method elements of our decision support tools of the TSS, namely MAGNET and Global-Detector. Chapter 3 describes the Ghana case study and the approach of the research, including the data needed for the decision support tools of TSS. The results of the availability of food, food consumption and virtual production circles, as all domestic demand around the city of Accra, are presented in Chapter 4. Finally, we will discuss and draw conclusions on the results and application of TSS. 


\section{Method for decision support tool}

The decision support tool of the TSS exists as two elements, e.g. scenario analyses and scaling tools (Dijkshoorn-Dekker et al. 2017). First we will discuss the economic MAGNET model. The outputs of MAGNET, which are calculated on a global or national level, give a general outline of changes that can be expected in food demand and land demand. These results can be downscaled to much smaller geographic maps with the tool Metropolitan Global-Detector (Paragraph 2.2.) to illustrate different developments in food consumption and food availability across metropolitan areas around the world.

\subsection{Economic model: MAGNET}

MAGNET is a multisector, multiregion computable general equilibrium model of the world economy (Woltjer et al. 2014), which has been widely used to simulate the impacts of agricultural, trade, land and biofuel policies on the global economy, as well as for long-term projections. MAGNET is based on the GTAP model, i.e. the model within the Global Trade Analysis Project, which accounts for the behaviour of households, firms and the government in the global economy and how they interact in markets (Hertel 1997). The model includes the food supply chain from the farm, as represented by agricultural sectors, via food processing industries and food service sectors to fork, taking into account bilateral trade flows for major countries and regions in the world. MAGNET has been extended from the GTAP model in a modular fashion to make it suitable for in-depth analyses in the area of agriculture, characterised by competing demands from food, feed and biofuels, and food and nutrition security. To quote Kuiper et al. (2017, p. 7):

The model yields a wide range of metrics to assess the performance of the food system both in terms of impact on natural resources (changes in agricultural land use, emissions) and food and nutrition security. MAGNET provides metrics at global and national level, and for household types in selected regions. The starting point for quantifying the global economy in MAGNET is the GTAP V9 database with base year 2007 (Narayanan et al. 2015). It distinguishes 140 countries or regions, 57 sectors and five factor endowments (land, unskilled labour, skilled labour, capital and natural resources). MAGNET is based on country input-output tables and includes consistent bilateral trade flows, transport and protection data. All monetary values of the data are in millions of US\$. Additional data sources include the International Energy Agency (IEA), the Food and Agriculture Organisation of the United Nations (FAO) and the United States Department of Agriculture (USDA).

Next to distinguishing different types of food, the possibility to distinguish sources of household income is important for analysing changes in consumption. In addition to the five GTAP production factors i.e. factor endowments, MAGNET can - for a selective number of countries for which suitable additional national data sources are available - distinguish more production factors. In combination with the household module this allows for a much more detailed assessment of changes in household income and thus in expenditure patterns (Kuiper and Shutes 2014).

Kuiper and Shutes (2014) have extended MAGNET with a household module. They stated that

The household module replaces the regional household, which collects income, saves and allocates income to the private household and government in the standard GTAP model, with explicit income flows to households and government. Households receive income from the supply of factor services, remittances, foreign income and transfers, and save a share of their income. The government receives income from tax revenues and aid payments and (dis)saves a share of its income which forms the internal balance. In this way, the separation of the household and the government introduces a direct link 
The model employed has 33 regions and 36 sectors, with 13 and 8 commodities in the primary production and the food processing industry respectively (Kuiper et al. 2017). For five countries including Ghana, Kuiper et al. distinguished multiple household types. These household types ranging from 2 to 10 household types varied with rural and urban residents and subdivisions on income levels or main sources of income. Land and labour endowments were adjusted accordingly. These subdivisions enhanced MAGNET's ability to track changes in sectors on household incomes. Annex A provides a detailed description of the model dimensions and additional data sources for the household regions.

\subsection{Global-Detector}

Global-Detector is a generic graphic tool for knowledge-based spatial analysis in a fast and straightforward way (Hennen et al. 2017). It aims to detect the worldwide potential for production, demand and market strategies. With a resolution of grids of $5^{\prime} \times 5^{\prime}$, the tool can show the values on any spot in the world for a large set of indicators, such as climate, infrastructure, demographics and land characteristics. The concept of Global-Detector is shown in Figure 2. Although the Global-Detector was designed for a worldwide scale, it can be downscaled to national and regional level. In those cases, the resolution can be increased.

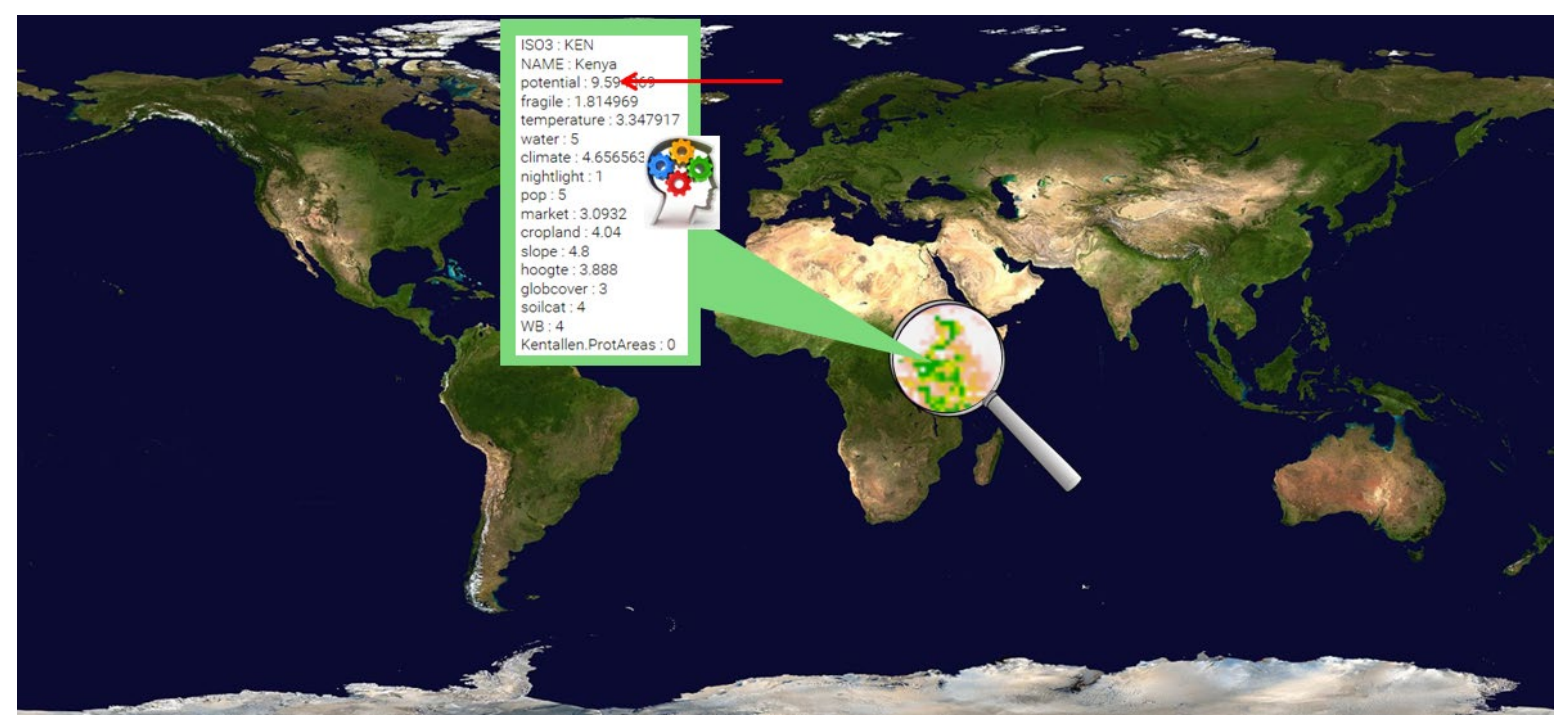

Figure 2 The concept of Global-Detector

For Global-Detector, there is a large set of indicators readily available for use without any GIS processing. The set includes indicators for climate (change), infrastructure, markets, land use and characteristics. In addition, there are also indicators on a country level (e.g. gross domestic product). In addition to the readily available indicators, the Global-Detector tool can also be used to map results from model exercises such as MAGNET. In this way, future projections of indicators can be mapped as well. This might require additional assumptions - see Chapter 4. 


\section{Urban food security in Ghana under different scenarios}

This chapter describes the case study of Ghana with a particular emphasis on Accra, the capital of Ghana. Section 3.1 discusses urbanisation and food security. Section 3.2 describes the future scenarios, population, household clusters, income per capita and commodities used to visualise the urgency of Ghana's future food security using the decision support tools of the TSS. The data used and the results derived therefrom on demographics and income per capita are from research unless explicitly indicated otherwise (Kuiper et al. 2017).

\subsection{Urbanisation and food security}

The population of Ghana grew from 5.0 million in 1950 to 26.4 million in 2014 while the urban share of the population has increased from $15 \%$ to $54 \%$ in 2015 (United Nations 2015). Figure 3 shows that the projections for the future Ghana populations indicate that the share of urban population will increase to $70.4 \%$ in 2050 (United Nations 2015), which is higher than the share for Africa $(55.9 \%)$ or western Africa (63.0\%) including Ghana.

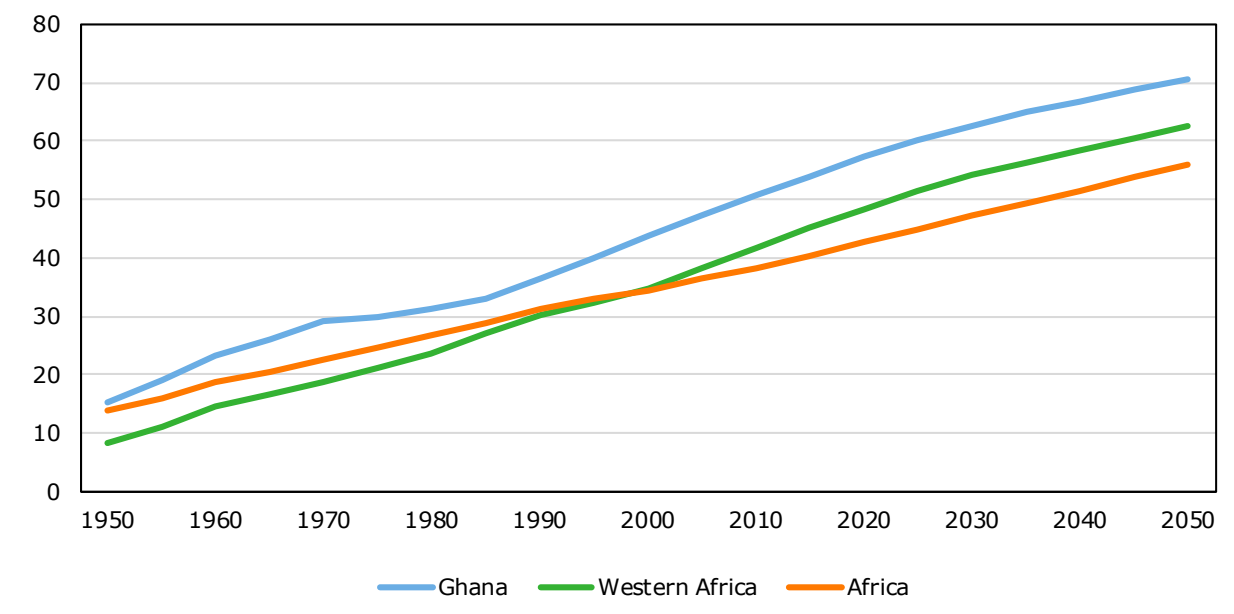

Figure 3 Share (\%) of urban population in Ghana, western Africa and Africa, 1950-2050 Source: United Nations (2015)

A major challenge is to feed the future population. Usually, the challenges of food security are targeted to the rural population involved in agricultural activities but poor urban households in lowincome countries could suffer even harder (Birhane et al. 2014) when food prices might increase due to unbalances between food supply and demand (Atkinson 1995). As rural households in low-income countries are involved in agricultural activities, they might benefit from higher food prices as well, while urban households not involved in agriculture do not. There is little empirical evidence on urban food security and how people living in urban areas are coping with sustained high food prices (Birhane et al. 2014). Birhane et al. (2014) studied the food insecurity situation in urban Ethiopia - a country experiencing sustained high food prices, high rates of urban poverty and a growing urban population. Three quarters of the urban households in Ethiopia experienced food insecurity mainly observed in low-income households and low-educated household heads.

Food and nutrition security policy should look beyond agricultural developments for several reasons (Shutes, Verma, and Kuiper 2015; M. Kuiper, Shutes, and Oudendag 2017)). First of all, price changes result in price and income effects, which need to be assessed to determine the food accessibility (Hertel 2016). Households earning an income in agriculture (farmers or labourers) will benefit from 
higher agricultural prices but net food consumers living in either rural or urban areas of low-income countries will be harmed. Conversely, net food consumers will benefit from lower agricultural prices, while households earning an income in agriculture will be harmed due to the low market prices. Either way, the size of the impact depends on a range of factors affecting price transmissions (Swinnen 2010). In addition, the share of urban population increases and this development alters the balance between winners and losers of price changes (Kuiper et al. 2017). This reasoning might induce a rationale to target future policies towards lowering agricultural prices, even though currently the majority of the poor benefit from higher agricultural prices (Headey and Martin 2016).

In the literature, there are a few examples that look at food security and food consumption of urban consumers. In Mozambique, for instance, urban residents spend $83 \%$ of their income on food (Garrett and Ruel 1999). In Accra (Ghana), families spend an average of $54 \%$ of their income on food (Maxwell 2000). A number of studies have shown that urban diets are strongly influenced by prices and incomes, but they are also influenced by lifestyles, social relationships, marriage patterns, family structures, the availability of packaged and processed foods, and advertising and the media (Atkinson 1995). A recent study in Accra showed there is high dietary diversity in the communities of Accra but a low consumption of foods rich in micronutrient, such as fruit and milk/dairy products (Codjoe et al. 2016). In particular, females, poor households, and the non-educated have food insecurity problems (Codjoe et al. 2016).

Given the rapid growth of the urban population in Ghana and the current issues with food security, the prospects for food security of the urban population in Ghana are unfavourable. Questions arise like: What are the food security prospects for urban population in Ghana given the high growth rates of urban population and the availability of domestic food? How well prepared is the society of Ghana including government, the private sector and citizens for these changes? Are these challenges already incorporated in policies in Ghana for instance?

In a systematic review of policies in Ghana, the relevant policies for urban food security (Linderhof et al. 2019). They adopted the food system framework for food security from Ingram, which linked three activities or outputs from the food system approach to three pillars of the food security definition namely food availability, food access and food utilisation (see Table 2). So, the policy review was done based on the nine food system elements rather than on the three pillars of food security. For convenience, stability, the fourth pillar of food security, was ignored because the policy review was a snapshot of the current situation and not an analysis over time. The overall conclusion was that the aspects of food security are still covered by the traditional policies: agriculture is mainly dealing with production, distribution and exchange of food. Nutritional value and food safety, for instance, are main concerns of the health and nutrition policy. However, Ghana is developing the Long-term National Development Plan (LTNDP) which combines several policies. Food safety is also considered more and more for the exchange of food from an export perspective: export requires particular food quality standards. The results of this review of the policies confirm that the integration of food security elements is still in an early stage of development. In addition, the urban aspect of food security was hardly considered in the policies relating to food security in Ghana.

Table 2 Definitions of the food system activities and drivers linked to the three food security outputs of the food system

\begin{tabular}{ll} 
Food security component & Activities/drivers of the food system \\
\hline Food availability & Production \\
\hline Food accessibility & Distribution \\
\hline & Exchange \\
\hline Food utilisation & Affordability \\
\hline & Allocation \\
\hline & Preference \\
\hline & Nutritional value \\
\hline
\end{tabular}

Source: (Linderhof et al. 2019) based on Ingram (2011) 


\subsection{The TSS approach to urban food security, Ghana}

\subsubsection{Future scenarios}

For this study we used results of the future projections of the economic MAGNET model for Ghana, taking into account changes of demand for food and supply of food in Ghana in the future for different socio-demographic scenarios (Kuiper et al. 2017). The scenarios of Kuiper et al. (2017) were projected to analyse sustainability and equity for different types of household in different countries, namely Ghana, India and China among others. The four scenarios were 1) ECO: (Ecotopia, aiming at a sustainable and equal world (high equity, high sustainability), 2) TLTL: Too little to late, aiming at economic growth (low equity, low sustainability), 3) ONEPW: One per cent world (low equity, high sustainability) and 4) FFANF: Food for all but not forever (low equity, low sustainability). These four food security scenarios have been developed through an interactive stakeholder process (van Dijk et al., 2015). The four scenarios are contrasting along two axes: sustainability and equality. Operationalisation of these scenarios for model-based food and nutrition security projections requires the definition of contrasting drivers reflecting the storyline in each world. The different scenarios and the economic consequences have been explored with MAGNET as well as other models in the project. The key drivers of the different scenarios were GDP, population and crop yield projections.

Based on four future scenarios, we selected two future scenarios based on the combination of equality and sustainability (van Dijk et al., 2015). We compare the results of those scenarios to the SSP2 scenario which is classified as a 'middle of the road' scenario by the IPCC (Riahi et al., 2017). So there are three scenarios:

- SSP2: Second shared socio-economic pathways, classified as middle of the road;

- ECO: Ecotopia, aiming at a sustainable and equal world;

- TLTL: Too little to late, aiming at economic growth i.e. inequality and an unsustainable world.

Scenarios are characterised by convergence between developing and developed regions. GDP and population growth in the ECO scenario are parameterised using the growth rates from the low mitigation and low adaptation challenge world of SSP1, with the exception that GDP per capita in highincome countries is lower than SSP2 with a structural change in around 2025 and 2035. The slow growth of TLTL is parameterised using the rates from the high-challenge world of SSP3. Population grows at a medium SSP2 rate in high-income countries and slower than SSP2 in all other regions.

\subsubsection{Demographic developments}

The population growth is the strongest under the SSP2 scenario. In 2007, Ghana had 22.5 million inhabitants and under the SSP2 scenario the population will grow to 46 million people in 2050, which is an annual population growth of $1.6 \%$. In the TLTL scenario, population in 2050 would be 42 million (annual growth of 1.4\%) and in the ECO scenario the population will be 39 million in 2050 (annual growth of $1.2 \%$ ). In the MAGNET results, it was assumed that the distribution of the different household clusters would not change over time.

Based on population development data from United Nations and urban development data from the World Bank, the annual population growth of Ghana is estimated at $2.12 \%$ per year and urban growth at $1.50 \%$ per year. Both rural and urban regions account for these increases by using an iterative allocation procedure. The maps in Figure 4 show the population density (logarithm of the population density per $\mathrm{km}^{2}$ ) in the current situation and projections for 2030 and 2050 . A green grid cell at the value of 3.5 means that the population density is 3,162 persons per $\mathrm{km}^{2}$, i.e. $10^{3.5} \approx 3,162$. A grid cell with value 1 would mean 10 persons per $\mathrm{km}^{2}$. 

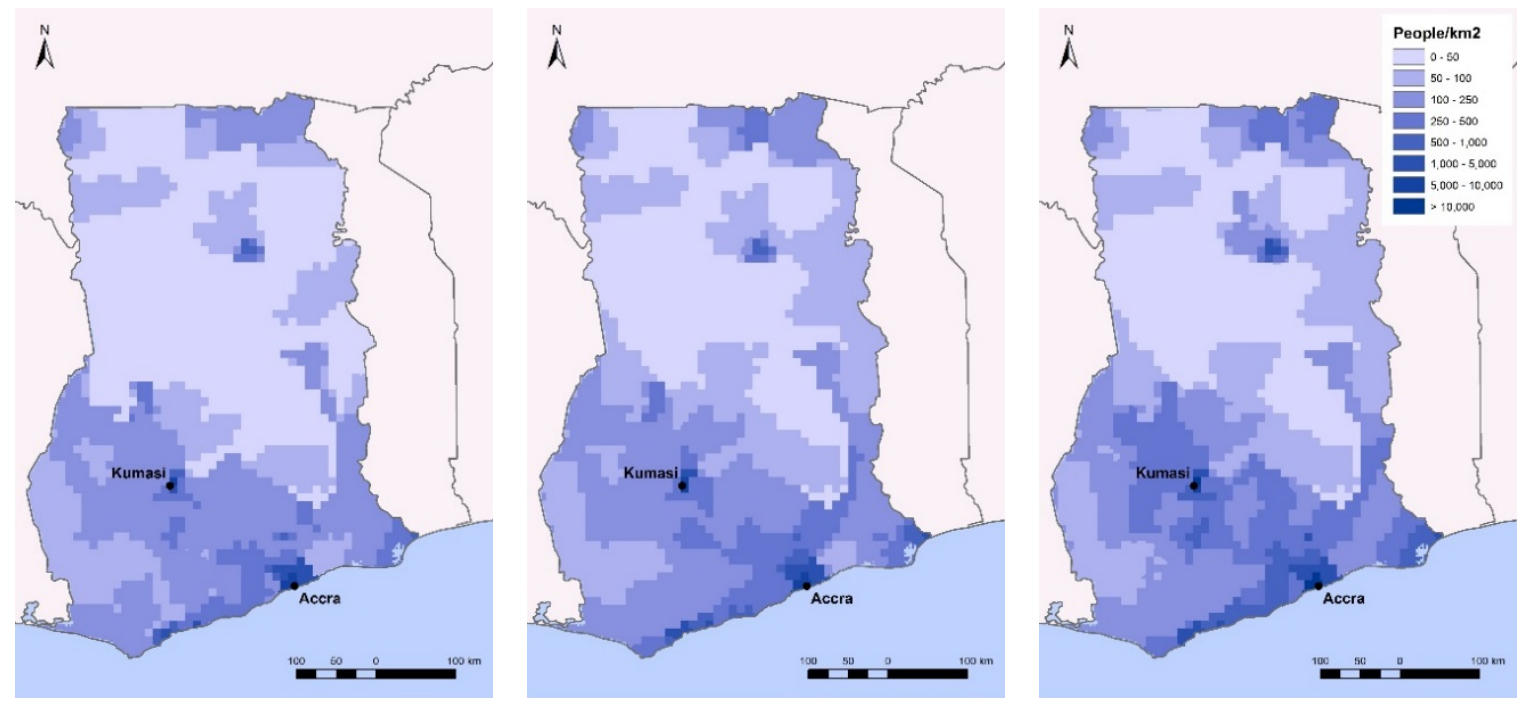

Figure 4 Development of population density from 2016 to 2050 (population per $\mathrm{km}^{2}$ )

Under the SSP2 scenario, the population of Ghana will increase from 22.5 million in 2007 to 35.6 million in 2030, and to 46.0 million in 2050.

\subsubsection{Household clusters}

Usually, MAGNET results are presented at country level. In the study, the households have been split up in clusters based on the location of households in the four agro-ecological zones (AEZ) within Ghana (Kuiper et al., 2017), namely Coastal, Forest, Savannah South and Savannah North, and on the urbanisation degree within these AEZs (rural/urban) (see Figure 5). The outcomes of MAGNET, usually presented as shares or developments over time, are combined with the indicators from GlobalDetector. The population results from MAGNET have to be translated into the maps based on the criteria mentioned above which results in eight household clusters: Coastal Urban, Forest Urban, Savannah South Urban, Savannah North Urban, Coastal Rural, Forest Rural, Savannah South Rural and Savannah North Rural. Figure 5 presents the 'degree of urbanisation' map from Global-Detector in 2010 within the four AEZs which indicates the locations of the households. The green and yellow coloured areas indicate high population densities. 


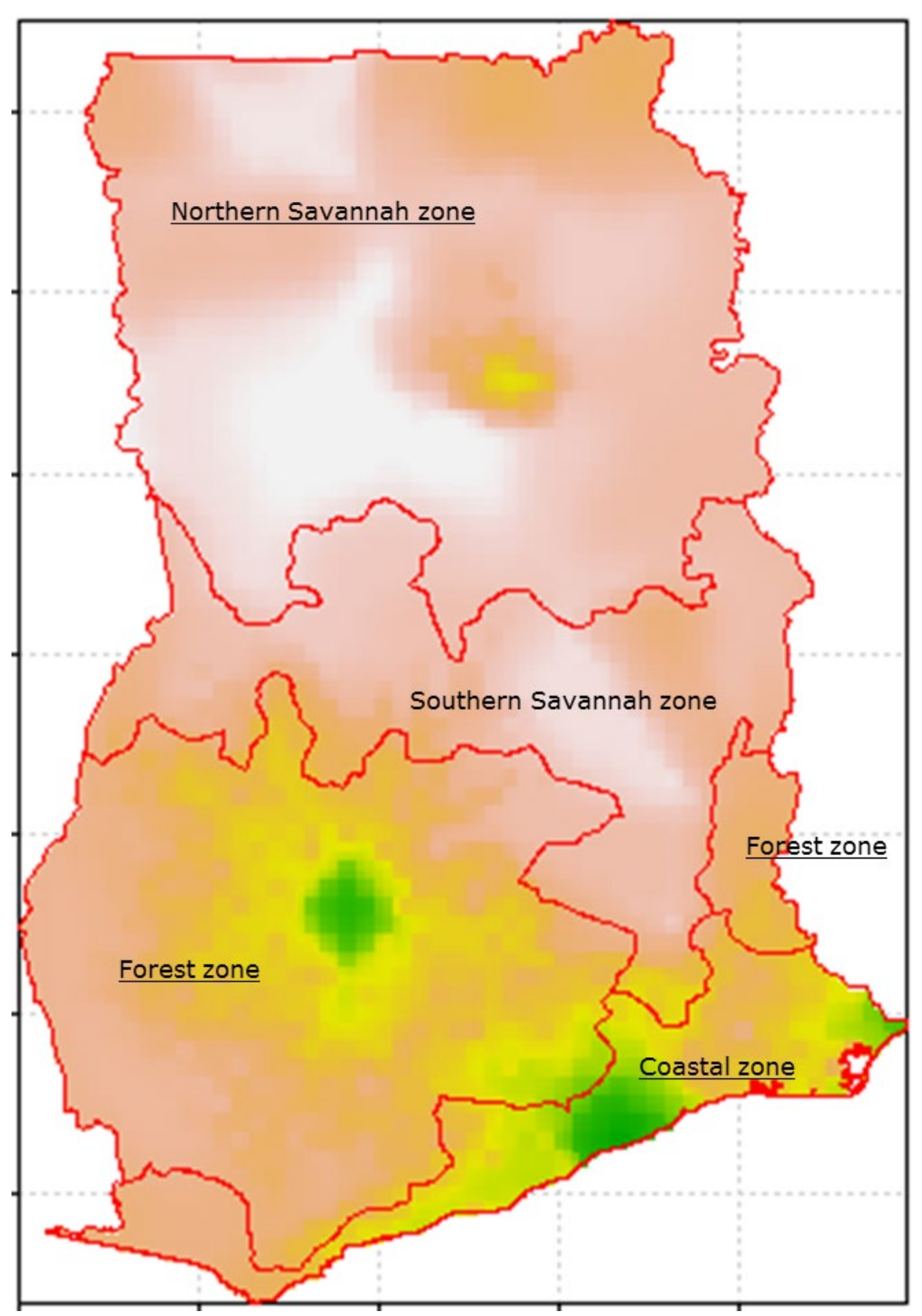

Figure $5 \quad$ Urbanisation map and the four agro-ecological zones in Ghana

For the household cluster urban coastal, we distinguish Greater Accra, the capital of Ghana and the rest of the urban coastal zone cluster. 
Table 3 Household clusters population (million) in Ghana, and population (million), area (1,000 km²) and population density (persons per km²) per province in Ghana in 2007

\begin{tabular}{|c|c|c|c|c|c|c|c|c|c|c|c|}
\hline \multirow[b]{2}{*}{ Household clusters } & \multicolumn{10}{|c|}{ Provinces of Ghana } & \multirow[t]{2}{*}{ Total } \\
\hline & Ashanti & Brong Ahafo & Central & Eastern & Greater Accra & Northern & Upper East & Upper West & Volta & Western & \\
\hline \multicolumn{12}{|l|}{ Urban } \\
\hline Greater Accra & & & & & 2.60 & & & & & & 2.60 \\
\hline Coastal & & & 0.53 & 0.16 & & & & & 0.14 & 0.40 & 1.22 \\
\hline Forest & 1.59 & 0.43 & 0.08 & 0.70 & & & & & 0.20 & 0.27 & 3.27 \\
\hline Savannah South & & 0.34 & & 0.07 & & & & & 0.09 & & 0.50 \\
\hline Savannah North & & & & & & 0.54 & 0.11 & 0.05 & & & 0.70 \\
\hline \multicolumn{12}{|l|}{ Rural } \\
\hline Coastal & & & 0.79 & 0.44 & 0.49 & & & & 0.46 & 0.33 & 2.50 \\
\hline Forest & 2.14 & 0.58 & 0.55 & 1.29 & & & & & 0.43 & 1.25 & 6.23 \\
\hline Savannah South & & 0.68 & & 0.33 & & & & & 0.35 & & 1.36 \\
\hline Savannah North & & & & & & 2.13 & 0.95 & 0.74 & & & 3.82 \\
\hline Ghana & 3.73 & 2.04 & 1.95 & 2.98 & 3.09 & 2.68 & 1.06 & 0.79 & 1.66 & 2.25 & 22.22 \\
\hline Area $\left(1,000 \mathrm{~km}^{2}\right)$ & 24.9 & 39.6 & 9.8 & 19.3 & 3.2 & 70.4 & 8.8 & 18.5 & 20.6 & 23.9 & 239.0 \\
\hline Population density & 150 & 51 & 198 & 154 & 953 & 38 & 120 & 43 & 81 & 94 & 93 \\
\hline
\end{tabular}

Source: Kuiper et al. (2017) 
Next to the population of the provinces and household clusters, Table 3 shows the population density of the provinces. As we are interested in food consumption in urban Accra, and the household cluster Greater Accra largely corresponds to the province Greater Accra, the population density in Accra is approximately 950 persons per $\mathrm{km}^{2}$, while the population density of Ghana is less than 100 persons per $\mathrm{km}^{2}$.

\subsubsection{Income per capita}

With MAGNET, the projections of income per capita are evaluated for the three different scenarios see Figure 6. In the SSP2 scenario, the index of income per capita for the household cluster Greater Accra, the blue line in the left panel of Figure 6, will increase from 125 in 2010 to 1,400 in 2050, which means an annual growth of income per capita of $5.6 \%$. This increase of income per capita for the household cluster 'Greater Accra' is larger than for all households in Ghana - see the blue line in the right panel of Figure 6.

In the ECO scenario, the income per capita would increase even more than in the SSP2 scenario. In the ECO scenario, the index of the income per capita of the household cluster Greater Accra increased from 125 to 1,800, which means an annual growth of 7\%. For the TLTL scenario, the income per capita increased less than in the SSP2 scenario. The index of the income per capita in the household cluster Greater Accra increased from 125 in 2010 to 660 in 2050, which is an annual growth of 3.5\%.

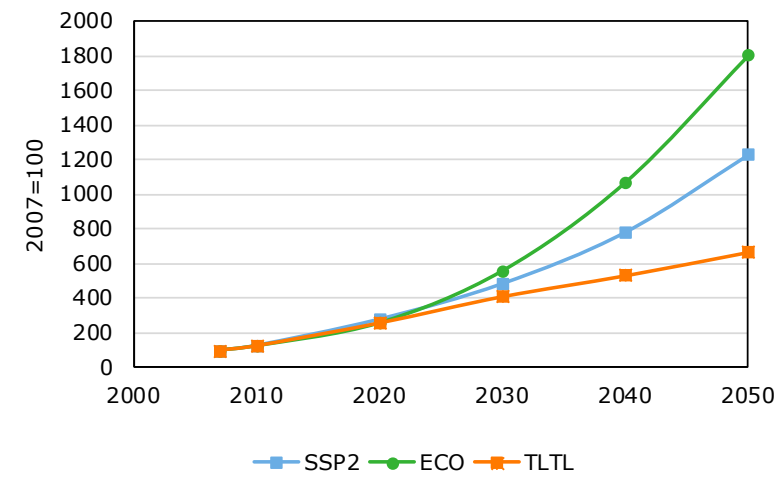

Greater Accra area

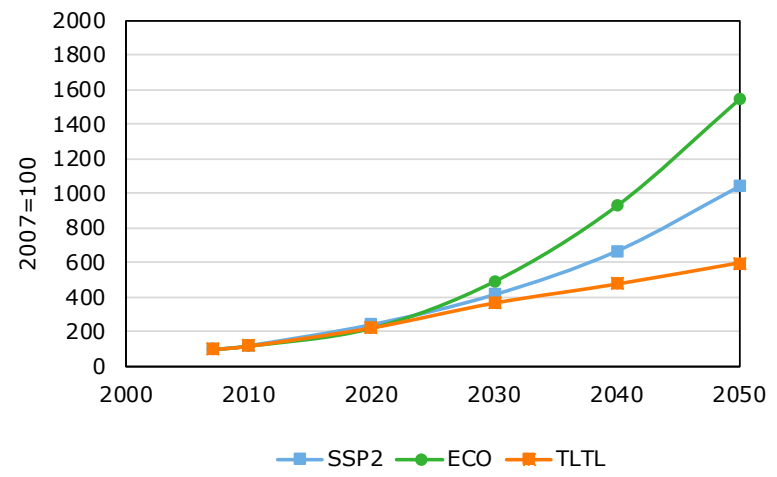

Ghana

Figure 6 Development of income per capita in the period 2007-2050 for Accra and Ghana for three different pathways. Source: MAGNET simulations (Kuiper et al., 2017)

Figure 6 shows that for all the three scenarios the increase in income per capita is higher for the household cluster Greater Accra than for all households in Ghana.

\subsubsection{Selection of food commodities}

The results of MAGNET distinguish eight different crop-related commodities and four livestock-related commodities (Kuiper et al. 2017). For a food consumption or food security analyses, the food commodities are defined rather broadly. As we are primarily interested in starting a discussion about the future urban food security (UFS) in Accra, we selected two food commodities. First, we will present vegetables and fruit (including nuts) as this is a food category which is often advocated for increased consumption. Second, we will present rice as it is one of the dominating cereals in the diet of the population of Ghana. In the case of both food commodities, Ghana is self-supporting at the moment but this is not guaranteed in the future projections. 


\section{$4 \quad$ Mapping urban food security in Ghana}

Based on the data and derived results of two main drivers, namely demographics and income per capita as described in Chapter 3, we discuss food security in urban Ghana in Section 4.1, the consumption per capita and share of expenditure of both food groups and the exploration of the market for both food groups. In Section 4.2 the production and consumption is mapped in order to see whether or not there is mobility of crop to food requirements. In particular, we are interested in the fulfilment of the consumption requirements of citizens of the urban area of Greater Accra. What would be the requirement of crop land for rice if we would like to feed the population of Accra in the different scenarios? Before we can answer this question, we first map both the current situation and future projections of production and consumption. In Section 4.2.1, we present the maps of production for 2010 and the projections for 2030 and 2050 under the different scenarios. Section 4.2.2 maps the consumption across Ghana for 2010 and the projections for 2030 and 2050. Supply and demand is compared in Section 4.2.4. Section 4.2.5 presents the virtual production on maps for the future projection to fulfil the demand for food in the urban area of Accra.

\subsection{Food security in urban Ghana}

\subsubsection{Production and consumption}

In economic terms, total consumption of a food item is equal to production, plus imports minus exports. Total consumption of a food item can be distinguished into private consumption and nonprivate consumption. Private consumption is related to consumption of households, while non-private consumption is related to government for instance. In this section, we are interested in whether or not private consumption of food items could be fully depend on domestic production of food crops. So, we explore the production of the food item in Ghana, the export of food items from Ghana, and the private consumption compared to the production of the food item. Note that we do not explore current or future food and nutrition security in this section.

\section{Vegetables and fruit}

In 2010, the production of vegetables and fruit in Ghana was worth more than USD 6.9 billion, while the export of vegetables and fruit amounted to approximately USD 232 million. Imports amounted to USD 50 million; thus, Ghana is a net exporter of vegetables and fruit.

Under the SSP2 scenario, production of vegetables and fruit will increase to 17.7 billion in 2050 which means an annual growth of production (annual growth of production of $2.4 \%$ ). In the case of the ECO scenario, production of vegetables and fruit will increase to even more than USD 18.2 billion, while in case of the TLTL scenario the production will increase to almost USD 13.7 billion. A similar trend is observed for the exports of vegetables and fruit under the three scenarios. Exports of vegetables and fruit increased to USD 1.5 billion in 2050 under SSP2, while it increased to USD 2.6 billion under the ECO scenario. For the TLTL scenario it increased but was limited to USD 764 million. Import of vegetables and fruit remain rather constant over the whole period and for all scenarios. 


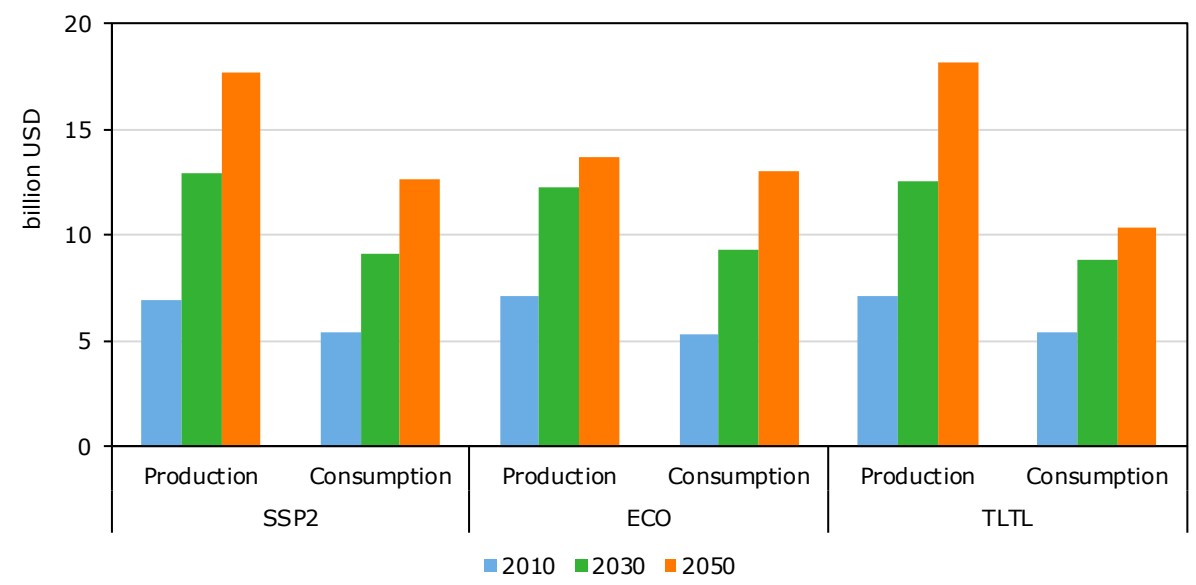

Figure 7 Production and consumption of vegetables and fruit in Ghana in 2010, 2030 and 2050 under the three scenarios

In Ghana, the consumption of vegetables and fruit is lower than production. In particular, the value of the production of vegetables and fruit in Ghana exceeded the value of the private consumption of vegetables and fruit in Ghana in 2010 for all scenarios see Figure 7. For the consumption of vegetables and fruit, consumption of home production was also valued at market prices.

Under the assumptions of the SSP2 scenario, production and consumption of vegetables and fruit will increase - see Figure 7. In the period 2010-2050, the value of the difference between production and consumption of vegetables and fruit in Ghana is expected to grow as well, which is also reflected by the increases in export of vegetables and fruit.

\section{Rice}

In 2010, the production of rice in Ghana amounted to USD 0.4 billion and the export of rice from Ghana was approximately USD 10 million. The import of rice into Ghana was less than USD 1 million. As a result, consumption including imports amounted to USD 390 million.

In the SSP2 scenario, the production of rice will increase to almost USD 1.5 billion in 2050, which means an annual growth rate of $3.3 \%$. In the ECO scenario, the production of rice in 2050 will amount to more than USD 1.7 billion, while in the TLTL scenario the production of rice in 2050 will be almost USD 1.2 billion. For export of rice, the results show a similar pattern. In the case of the SSP2 scenario, the export of rice will increase to almost USD 700 million in 2050, which means an annual growth of more than $11 \%$. For the ECO scenario, the export of rice will be almost USD 1 billion and for the TLTL scenario it will be almost USD 0.5 billion. The import of rice in 2050 will decline; see table in the appendix.

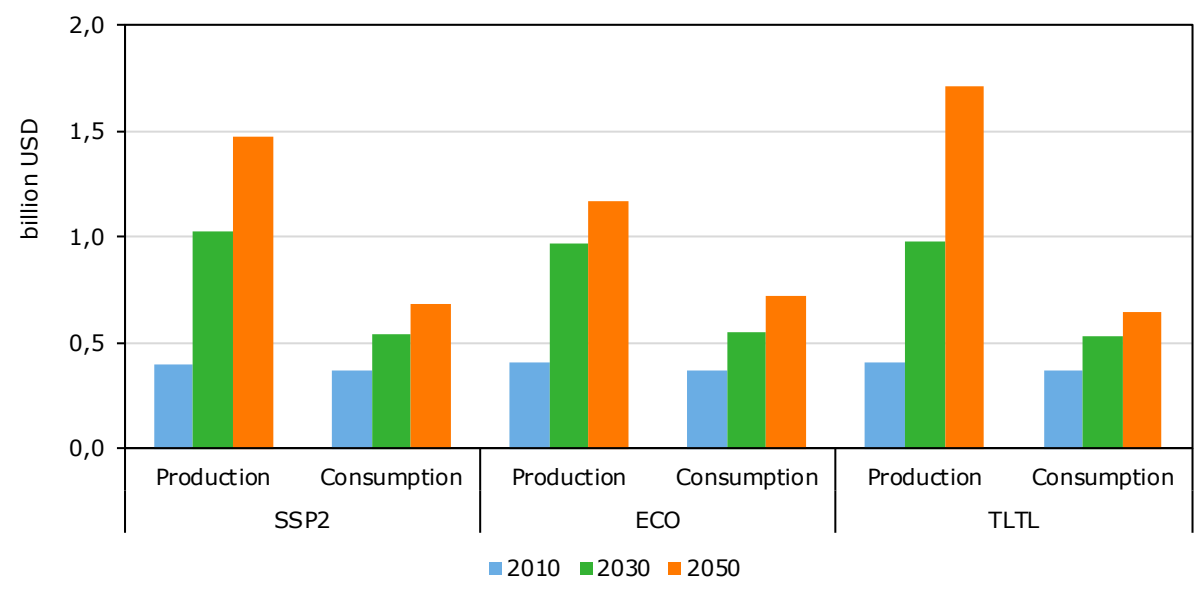

Figure 8 Production and consumption of paddy rice in Ghana in 2010, 2030 and 2050 under the three scenarios 
For rice, the production of rice in Ghana exceeds the consumption of rice in 2010, as shown in Figure 8. For the future projections, the production of rice will increase in all scenarios much faster than the consumption of rice.

\subsubsection{Per capita consumption}

This section describes the value of consumption. The value of consumption includes the expenditure on the food items as well as the consumption of home production. This consumption of home production is then valued at market prices in the community. In the MAGNET results, this value of consumption is referred to as expenditure so that consumption in the countries from high, middle and low-income countries is comparable. The MAGNET results also distinguish between private consumption and non-private consumption. Private consumption is the consumption of households in Ghana. For the calculations in this section, we only use the private expenditure per capita from MAGNET and relate it to the income per capita as presented in Section 3.2.

Vegetables and fruit

The per capita consumption of vegetables and fruit increased between 2010 and 2050 for all three scenarios (see Table 4). In the SSP2 scenario, the consumption of vegetables and fruit per capita increased from USD 28 in 2010 to almost USD 36 in 2050. For the ECO scenario, the consumption in 2050 was USD 40 and for the TLTL scenario the consumption in 2050 was more than USD 30 . In the same period, the income per capita increased much faster than the per capita consumption of vegetables and fruit, so we expect the share of consumption of vegetables and fruit to decline in 2050 .

Table 4 Per capita consumption of vegetables and fruit (USD) in 2010, 2030 and 2050 per type of area for three scenarios

\begin{tabular}{lrrrrrrrrr} 
& \multicolumn{1}{c}{ SSP2 } & \multicolumn{3}{c}{ ECO } & & & TLTL \\
\cline { 2 - 9 } Area & 2010 & 2030 & 2050 & 2010 & 2030 & 2050 & 2010 & 2030 & 2050 \\
Urban Greater Accra & 32.7 & 39.4 & 41.9 & 33.1 & 40.9 & 46.0 & 33.1 & 38.8 & 37.2 \\
\hline Other urban areas & 18.7 & 22.2 & 23.8 & 19.0 & 23.1 & 26.4 & 19.0 & 21.9 & 20.9 \\
\hline Rural areas & 31.0 & 36.4 & 39.7 & 31.5 & 38.2 & 45.1 & 31.5 & 35.9 & 33.9 \\
\hline Ghana & 28.0 & 33.1 & 35.9 & 28.4 & 34.6 & 40.4 & 28.4 & 32.6 & 30.9 \\
\hline
\end{tabular}

In Ghana, the share of vegetables and fruit consumption was $2.3 \%$ in 2010 (all scenarios). In 2050, this share will drop to $0.35 \%$ in the SSP2 scenario. In the ECO scenario, the share of consumption is even lower $(0.26 \%)$ despite the higher consumption in this scenario compared to the SSP scenario. In the TLTL scenario the share of consumption is $0.52 \%$. In the SSP2 scenario is higher than in both the SSP2 and ECO scenarios.

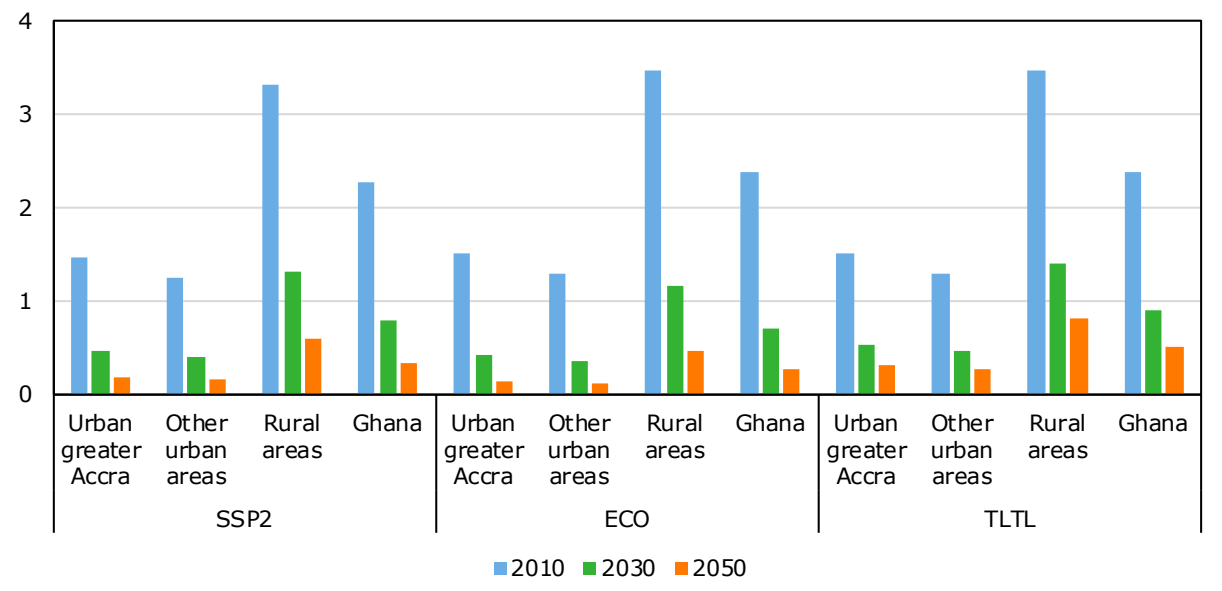

Figure 9 Share of consumption of vegetables and fruit per capita (\%) 
Figure 9 shows the share of per capita income spent on vegetables and fruit over time under different scenarios for urban and rural households. On average, rural households spend a higher share of their income on vegetables and fruit. As mentioned previously, home consumption is also valued at market price and incorporated into the per capita consumption. When we assume that the prices for vegetables and fruit in urban and rural areas are similar; the per capita consumption of vegetable and fruit is higher in rural areas.

Rice

The per capita consumption of rice in Ghana has slightly increased in the period 2010-2050 for the SSP2 scenario (see Table 5). In the ECO scenario, the increase of per capita rice consumption is even larger, while in the TLTL scenario, the per capita rice consumption has declined. This decline of the per capita rice consumption in the TLTL scenario is mainly due to a decline of rice consumption in the rural areas.

Table 5 Per capita consumption of rice (USD) in 2010, 2030 and 2050 per type of area for three scenarios

\begin{tabular}{lrrrrrrrrr} 
& SSP2 & \multicolumn{1}{c}{ ECO } & \multicolumn{1}{c}{ TLTL } \\
\cline { 2 - 9 } Area & 2010 & 2030 & 2050 & 2010 & 2030 & 2050 & 2010 & 2030 & 2050 \\
Urban Greater Accra & 2.98 & 3.07 & 3.09 & 2.99 & 3.21 & 3.43 & 2.99 & 3.05 & 3.01 \\
\hline Other urban areas & 1.62 & 1.72 & 1.73 & 1.63 & 1.79 & 1.91 & 1.63 & 1.70 & 1.68 \\
\hline Rural areas & 1.86 & 1.85 & 1.88 & 1.86 & 1.92 & 2.08 & 1.86 & 1.84 & 1.81 \\
\hline Ghana & 1.93 & 1.96 & 1.98 & 1.93 & 2.04 & 2.20 & 1.93 & 1.95 & 1.92 \\
\hline
\end{tabular}

The relative income spend on the consumption of rice is very low (less than $0.5 \%$ ). Figure 10 presents the share of per capita consumption of rice. In 2010, the share of rice consumption per capita was $0.16 \%$ of income. In 2050, the share will decline to $0.019,0.014$ and 0.032 for the SSP2, ECO and TLTL scenarios respectively. The decline of shares in income is mainly caused by the sharp increases in income during the same period (see Section 3.2).

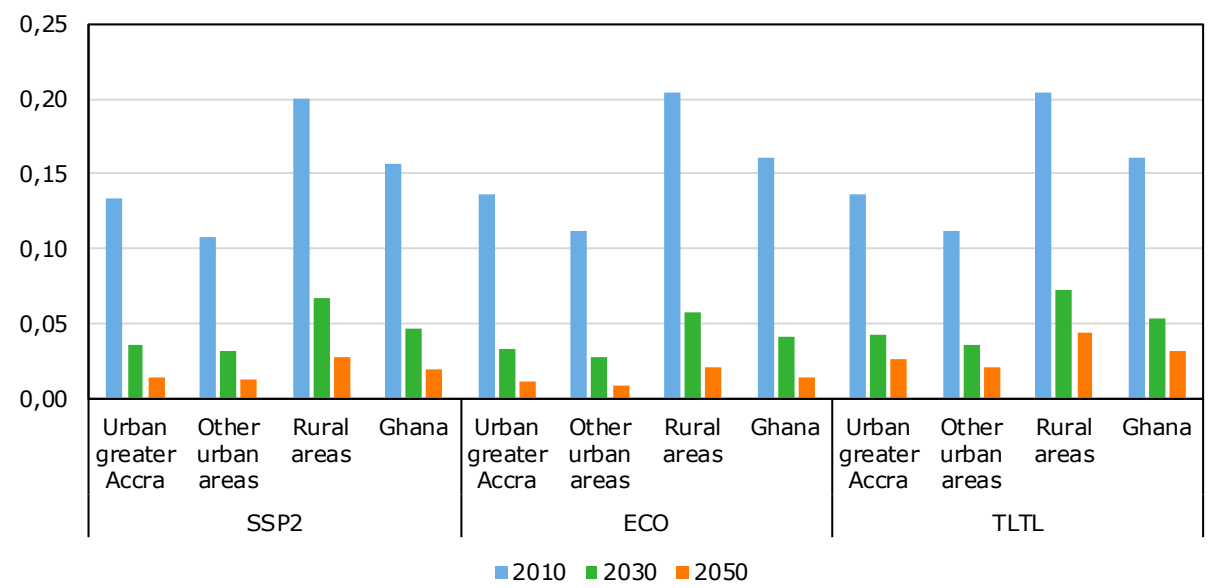

Figure 10 Share of consumption on paddy rice (\%)

Figure 10 shows that the share of per capita rice consumption in rural areas is higher than in the urban areas. Also, the share of rice consumption in 2050 in the TLTL scenario is slightly higher than for the SSP2 and ECO scenarios. 


\subsection{Mapping production and consumption}

\subsubsection{Production maps}

For the mapping of crop production, there are maps on crop lands available taking into account the type of cropland. In the case of Ghana, the resolution of the grid can be increased from $5^{\prime} \times 5^{\prime}$ grid cells (approximately $10 \times 10 \mathrm{~km}$ ) to $2.5 \times 2.5 \mathrm{~km}$ gird cells. Figure 11 below illustrates the transformed map for Ghana showing the area of cropland (in hectares per $2.5 \times 2.5 \mathrm{~km}$ grid cell) processed from the source www.earthstat.org. For Ghana, a total number of 38,228 grid cells are distinguished. The country is divided into four agro-ecological zones separated by red borders. All visualisations and calculations in this study are performed with this resolution. The surface of each grid cell is 625 ha. Based on the future total production in Ghana for a certain year and given the crop land maps, Global-Detector has a procedure to assign future production volumes to the crop land maps based on a number of assumptions, which are the following.

- Allocation of feasible cropping area given:

1. decrease of available cropping area due to population development,

2. current cropping area, and

3. if available, the remaining cropping area not assigned to a particular crop;

- Available areas per grid for the selected commodity (crop itself or proxy crops, e.g. cassava, yam and nuts for vegetables, fruit and nuts);

- Required area for crop production based on the total crop production from MAGNET and needed area derived from estimated production (USD per ha).

The map in Figure 11 illustrates the available crop land in Ghana divided over the different grid cells with Global-Detector. The dark green colour in Figure 11 means that 600 hectares of the grid cell i.e. 625 hectares - is cropland. The yellow areas reflect grid cells with approximately 300 hectares of croplands. Ultimately, the white grid cells have no croplands at all.

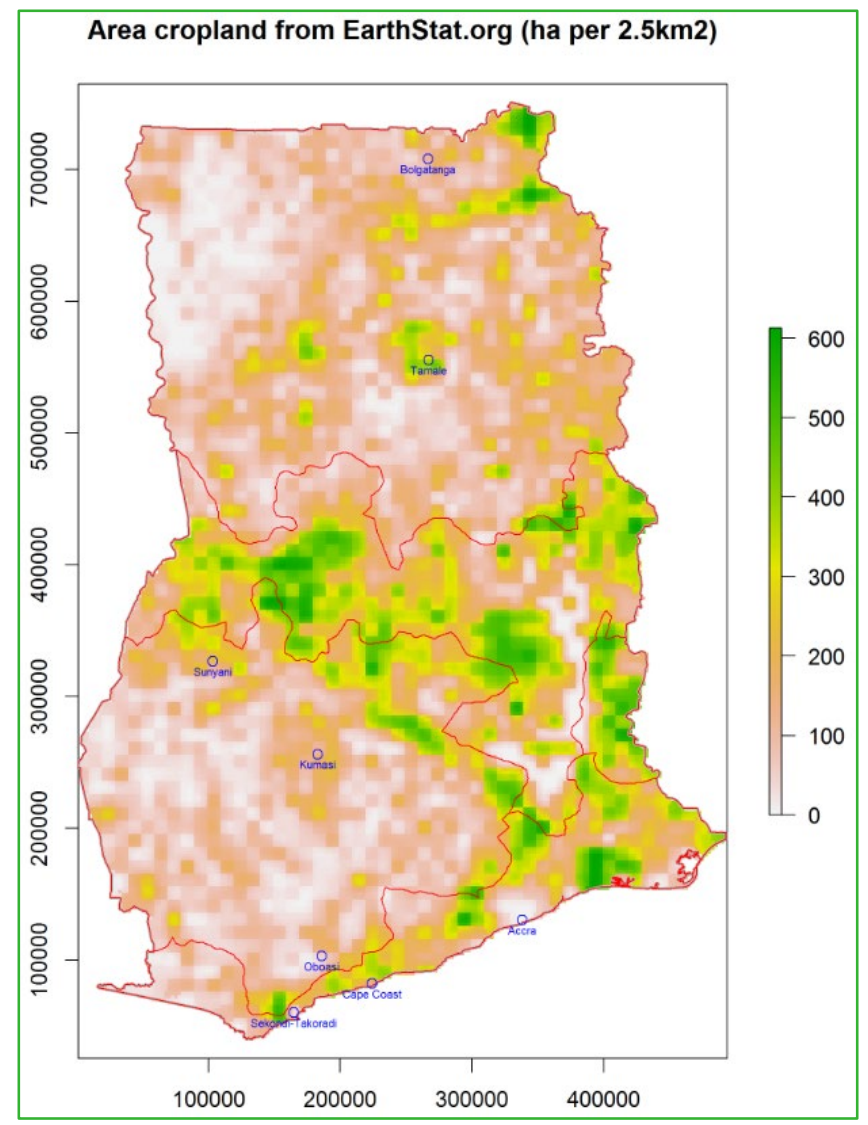

Figure 4 Illustration of crop land for Ghana based on grid cells of $2.5 \mathrm{~km} \times 2.5 \mathrm{~km}$ (GlobalDetector) 


\section{Vegetables and fruit}

As the type of commodities in MAGNET do not fully correspond to the commodities distinguished in Global-Detector, we use the production areas for cassava, yam and nuts in Global-Detector as proxy for the commodity vegetables and fruit from MAGNET. For the required area, we take into account three aspects: i) the production of vegetables and fruit from the MAGNET results, which show an increase from 2030 to 2050 (see Section 3.3), ii) the area available for crop land being reduced by the increased urban areas due to population growth, and iii) a gradual productivity yield increase in the period 2010-2050 based on the MAGNET results for each scenario.

Table 6 Annual growth of production and productivity of vegetables and fruit in different time periods under different scenarios

\begin{tabular}{llrrr} 
Scenarios & Indicator & $2010-2030$ & $2030-2050$ & $2010-2050$ \\
SSP2 & Production & 3.19 & 1.56 & 2.37 \\
\hline & Productivity per ha & 2.40 & 2.67 \\
\hline ECO & Production & 2.88 & 1.87 & 2.37 \\
\hline & Productivity per ha & 2.75 & 2.61 \\
\hline TLTL & Production & 2.79 & 0.54 & 1.66 \\
\hline & Productivity per ha & 1.61 & 0.91 \\
\hline
\end{tabular}

Note: If production growth exceeds productivity growth this indicates land area increases for production.

Table 6 shows the annual growth of production and productivity of vegetables and fruit in Ghana in the period 2010-2050. In the case of the SSP2 and TLTL scenarios, the production growth in the whole period is larger than the growth in productivity, which means that the area for vegetables and fruit production increases as well. In the ECO scenario, productivity grows faster than production, which means that less production area is required compared to the reference scenario.

For all scenarios, the growth rates for production and productivity are higher in the period 2010-2030 compared to the period 2030-2050. In the SSP2 scenario, land area for vegetables and fruit production increases in the period 2010-2030 because production growth exceeds productivity growth, but land area decreases in the period 2030-2050 because productivity growth exceeds production growth. Over the whole period, land size for vegetables and fruit production increases under the SSP2 scenario.

In the ECO scenario, land area for vegetable and fruit production increases in the first period and decreases in the second period. Overall, the land area for production decreases. In the TLTL scenario, the land area for vegetables and fruit production increases for both periods.

Figure 12 shows on the left the map of areas with vegetable and fruit production in Ghana in 2010, and in the centre and on the right the expected changes in production area under the SSP2 Scenario in 2030 and 2050, respectively. The green and red areas on the maps imply that the cropping area for vegetables and fruit has changed. Two divergent trends can be observed. In the surroundings of Accra and Kumasi, the area used for production of vegetables and fruit tends to decrease, as the result of the expansion of urban settlements in these regions. At the same time, the production area increases in rural regions nearby these metropolitan areas, in order to meet the increased consumption resulting from population growth. However, we can also observe that less land is required in 2050 compared to 2030, despite the steady increase in vegetable and fruit consumption, since the productivity growth rate is larger than the rise in production. 


\section{Vegetable and fruit 2010}

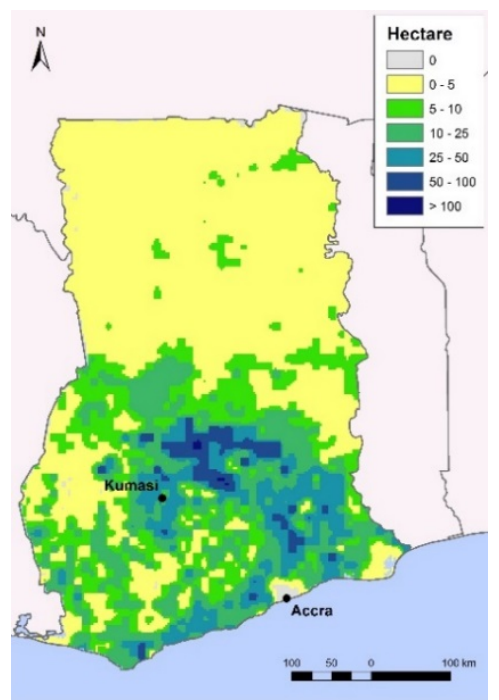

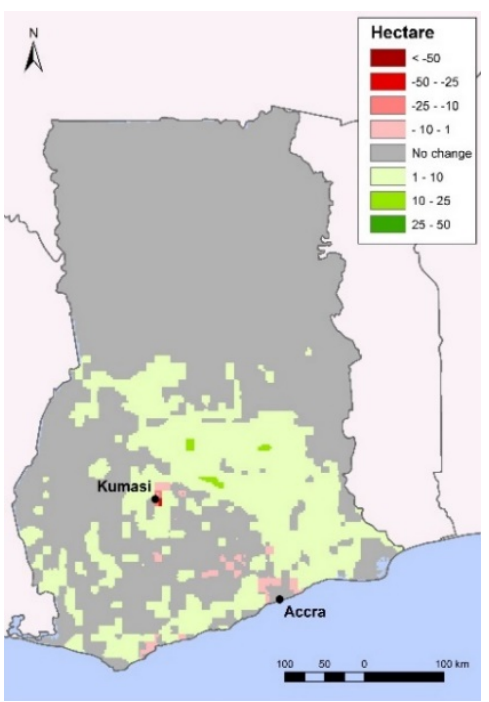

Change 2010-2050

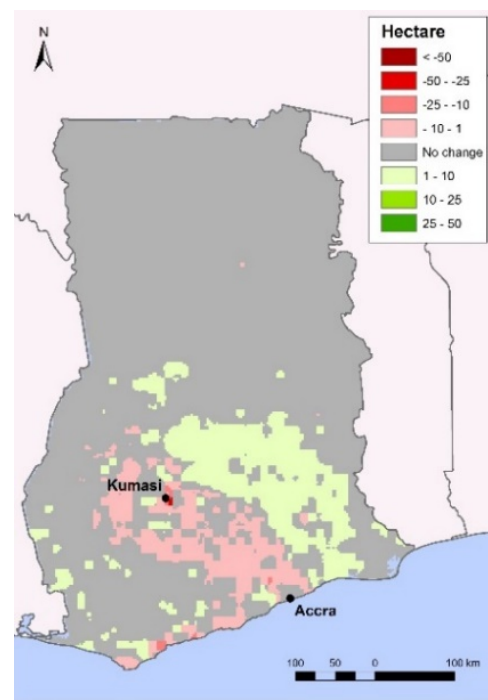

Figure 52 Changes in vegetable, fruit and nut production areas in 2030 and 2050 for the SSP2 scenario

Figure 12 reflects the change in production areas for vegetables and fruit in the ECO scenario. An overall decrease in production area is expected according to this scenario, in some areas up to more than 50 hectares. This is due to i) the high productivity of vegetables and fruit compared to the SSP2 scenario, and ii) the relative high population growth and thus expansion of urban areas, which means less crop land available in the vicinity of Accra and Kumasi urban areas.

Vegetables and fruit 2010

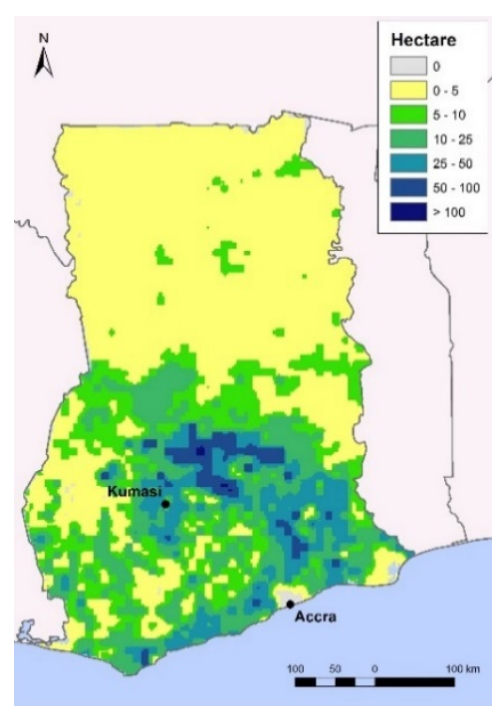

Change 2010-2030

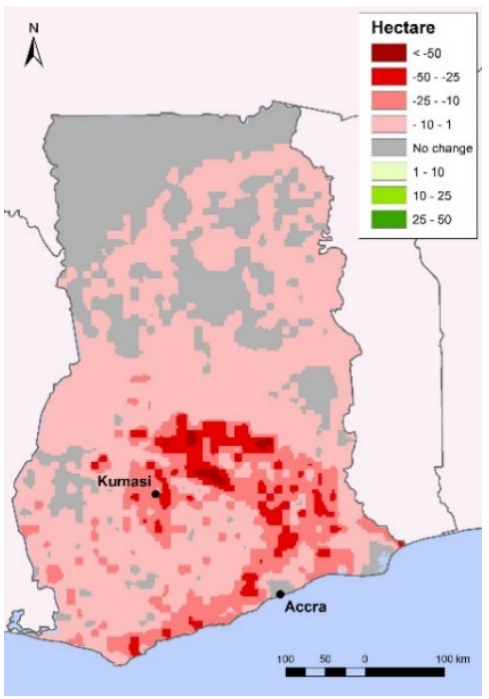

Change 2010-2050

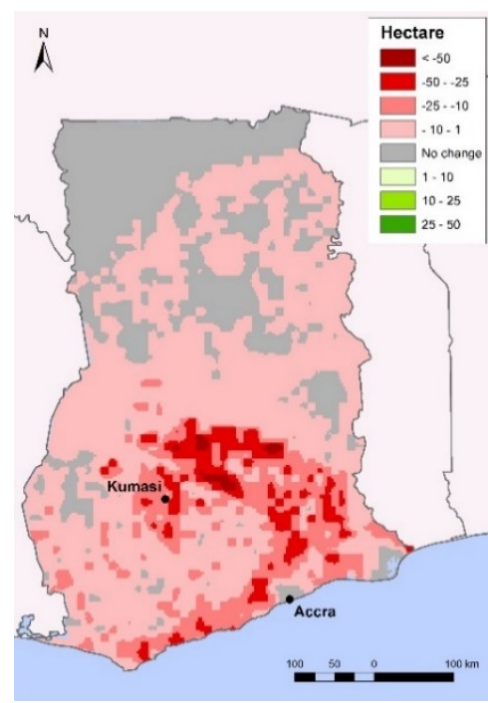

Figure 6 Changes in vegetable and fruit production areas (ha) in 2030 and 2050 in the ECO scenario

Figure 13 shows the results regarding changes in areas used for vegetable and fruit production in 2030 and 2050 according to the TLTL scenario. The patterns of this scenario are somewhat similar to the ones observed in the SSP2 scenario. However, in this scenario more land is required to produce the expected demand for vegetables and fruit, despite a smaller increase in production compared to the SSP2 scenario, due to a considerably lower productivity growth rate. In some areas, this increase can amount to more than 50 ha. 


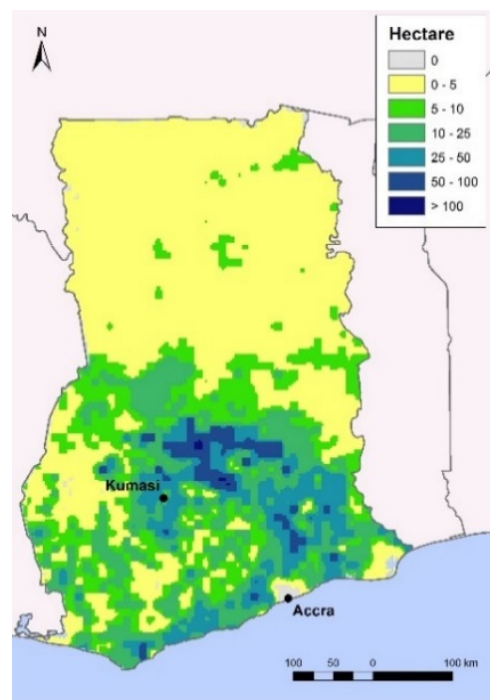

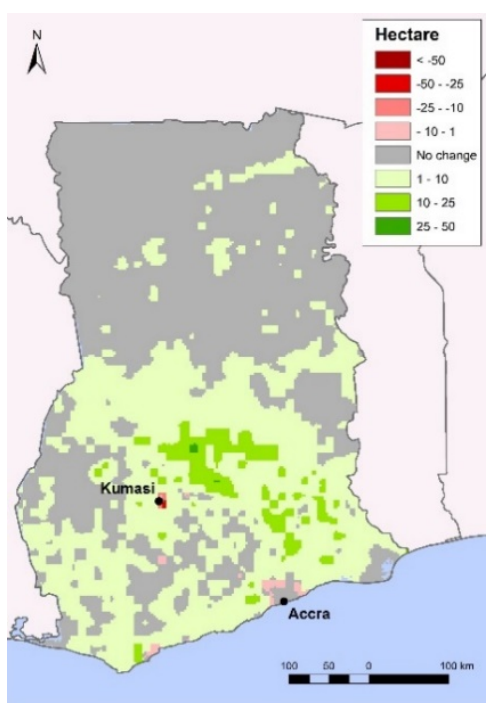

Change 2010-2050

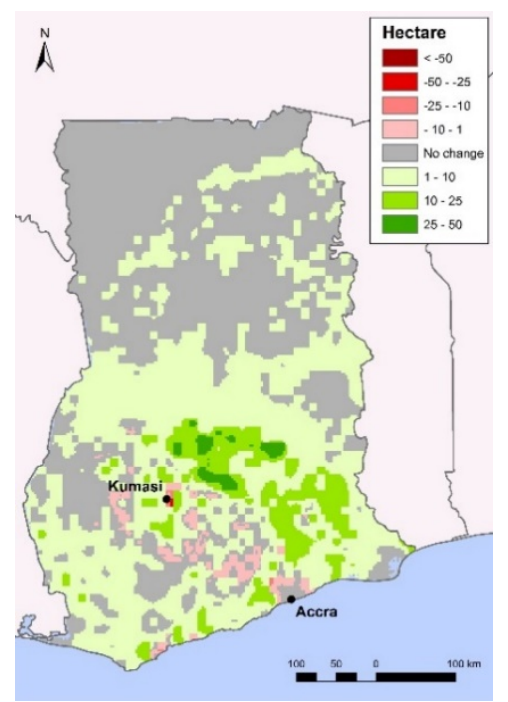

Figure 74 Changes in vegetable and fruit production areas (ha) in 2030 and 2050 in the TLTL scenario

\section{Rice}

Table 7 shows the annual growth of production and productivity of vegetables and fruit in Ghana in the period 2010-2050. In all scenarios, the production growth in the whole period is larger than the growth of productivity. The growth rates for rice production and rice productivity decline in the second period for all scenarios, which is similar to the trend observed for vegetables and fruit. In the SSP2 and ECO scenarios, the rice productivity growth in the second period (2030-2050) exceeds the rice production growth, while the reverse was the case for the first period (2010-2030). In the SSP2 and TLTL scenarios, production grows faster than productivity in both periods.

Table 7 Annual growth of production and productivity of rice in different time periods under different scenarios

\begin{tabular}{llrrr} 
Scenarios & Indicator & $2010-2030$ & $2030-2050$ & $2010-2050$ \\
SSP2 & Production & 4.79 & 1.86 & 3.31 \\
\hline & Productivity per ha & 3.49 & 1.66 & 2.57 \\
\hline ECO & Production & 4.50 & 2.83 & 3.66 \\
\hline & Productivity per ha & 4.09 & 3.11 & 3.60 \\
\hline TLTL & Production & 4.43 & 0.93 & 2.67 \\
\hline & Productivity per ha & 2.85 & 0.52 & 1.68 \\
\hline
\end{tabular}

Note: If production growth exceeds productivity growth this indicates land area increases for production.

Figure 15 shows on the left the map of rice production areas in Ghana in 2010, and in the centre and on the right the expected changes in production area under the SSP2 scenario in 2030 and 2050, respectively. We can observe that the production of rice is relatively limited, usually not exceeding more than 2 ha. The green areas in the change maps imply that the cropping area for rice can be expected to expand according to the SSP2 scenario, although this increase is relatively limited to less than 1.0 ha. Concurrently, a marginal reduction in the rice production area can be observed in a few urban areas, particularly in the urban core of Kumasi. 

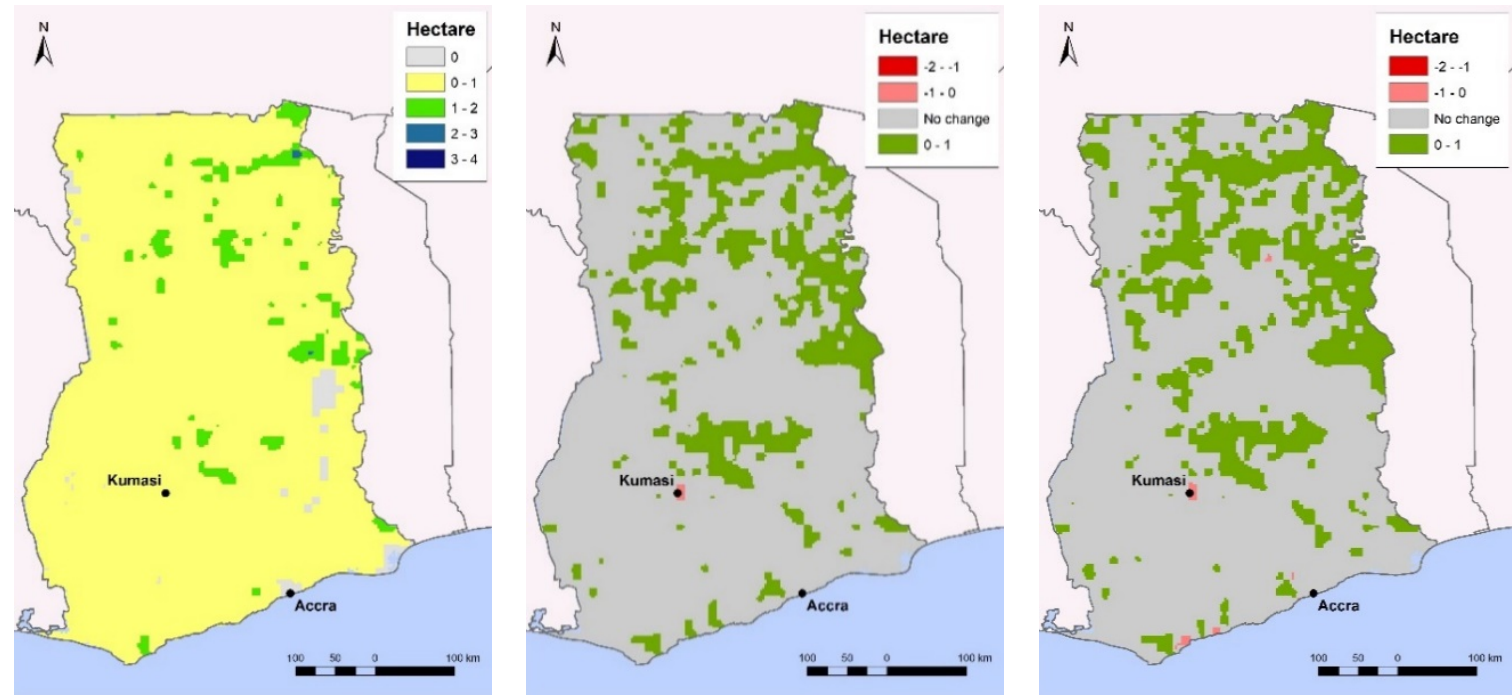

Figure 85 Changes in rice production for 2030 and 2050 in the SSP2 scenario

Figure 16 shows that all rice production areas are expected to decrease in the ECO scenario for 2030 and 2050. This is mainly due to the higher rice productivity according to this scenario, which results in less cropping land being put into rice production. However, the declines in production area are overall rather modest, ranging from 0.1 to 1.0 ha.

Rice 2010

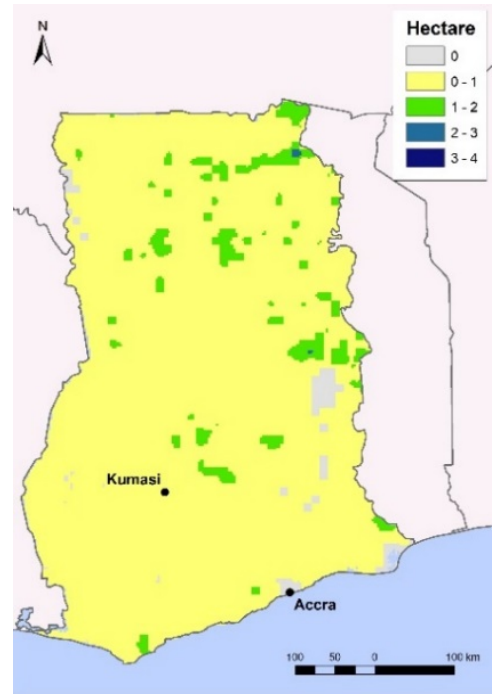

Change 2010-2030

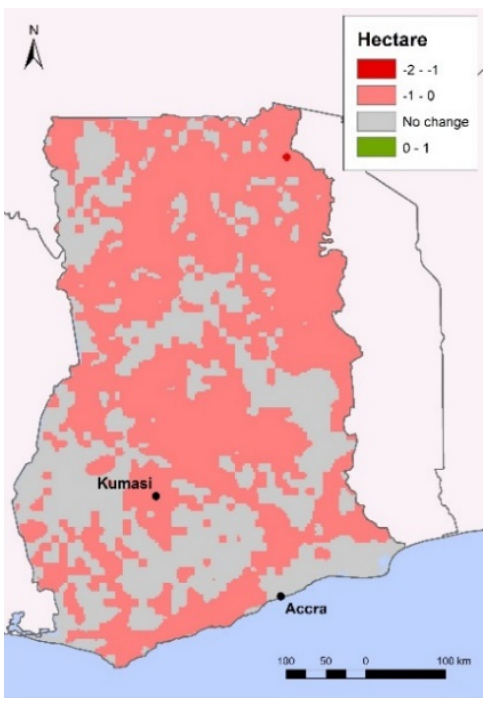

Change $2010-2050$

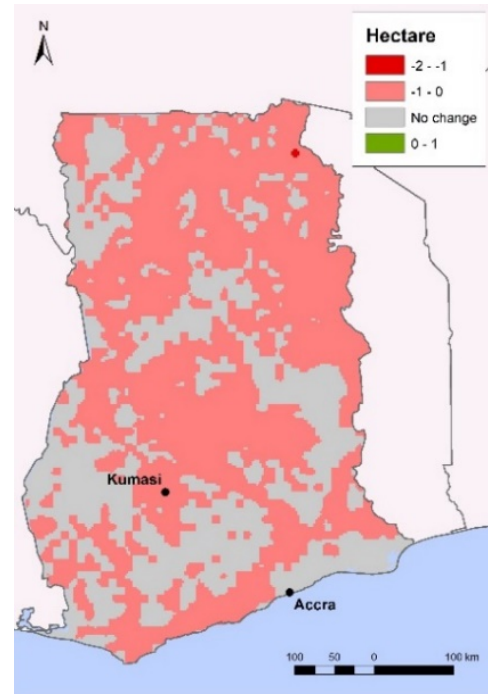

Figure 9 Changes in rice production areas (ha) in 2030 and 2050 in the ECO scenario

In the TLTL scenario, we observe the opposite trend compared to the ECO scenario. Furthermore, the distribution of rice cropping area increase is more widespread than in the SSP2 scenario. This is mainly due to the fact that rice productivity under TLTL is significant lower, being this compensated with more land being put into rice production. However, the increases in production area are somewhat marginal, ranging from 0.1 to 0.5 ha. 

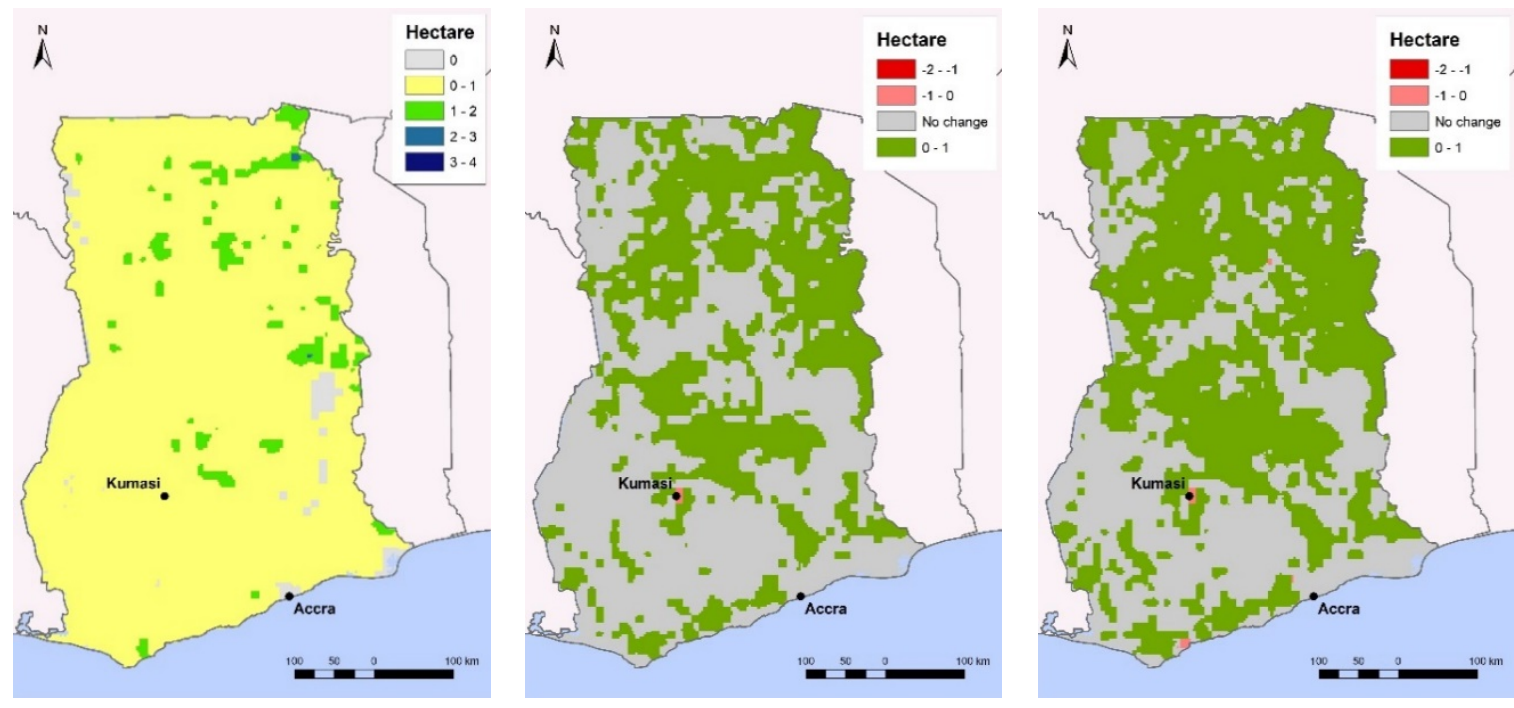

Figure 107 Changes in rice production areas (ha) in 2030 and 2050 in the TLTL scenario

\subsubsection{Consumption maps}

For the mapping of consumption of vegetables and fruit, and rice, we rely on the available population maps. From MAGNET, we know the per capita consumption in values (see Table 6 for vegetables and fruit, and Table 7 for rice), and we know the population per grid cell. The results reflect differences in per capita consumption across household clusters distinguished. Per grid cell, we calculate the value of consumption, which is the population multiplied by the per capita consumption per grid cell. Figure 18 shows the development of vegetables and fruit consumption over time for the SSP2 scenario. The maps for 2030 and 2050 show changes in patterns of higher consumption, particularly in the urban core of Greater Accra and Kumasi metropolitan areas, where an increase of more than 250 tonne/ $\mathrm{km}^{2}$ can be expected in 2050 compared to 2010 .

Given the stark spatial heterogeneity in terms of consumption increase, the maps for the other scenarios present similar patterns and therefore we do not include them in this report. For rice, we also obtain similar patterns but with different scales of consumption, since per capita rice consumption is much lower than consumption of vegetables and fruit. 


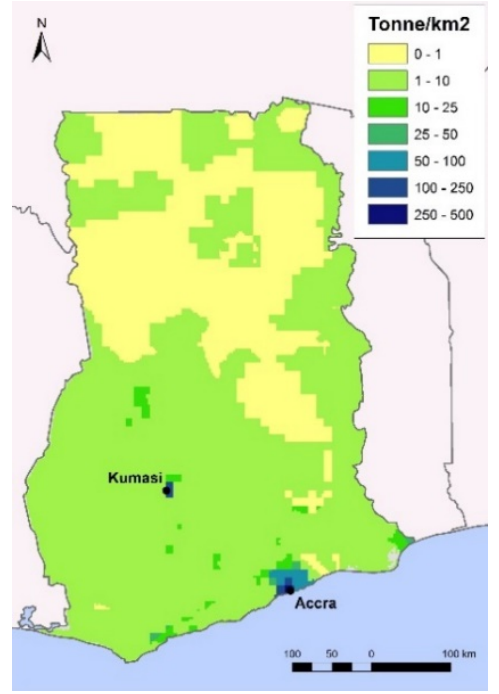

Rice 2010

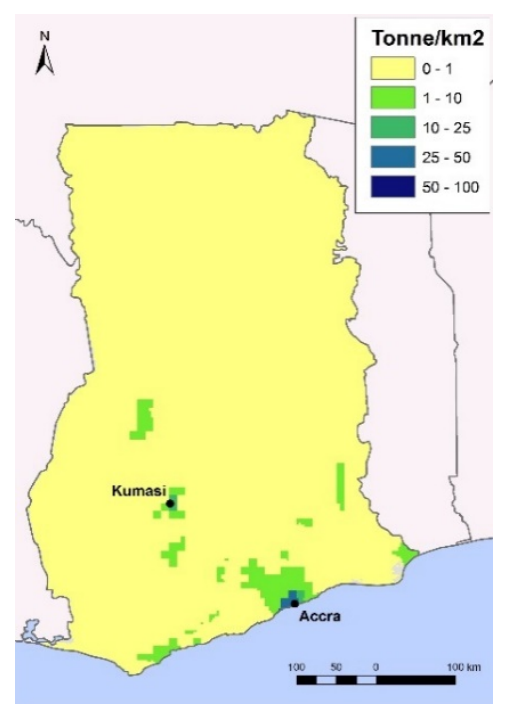

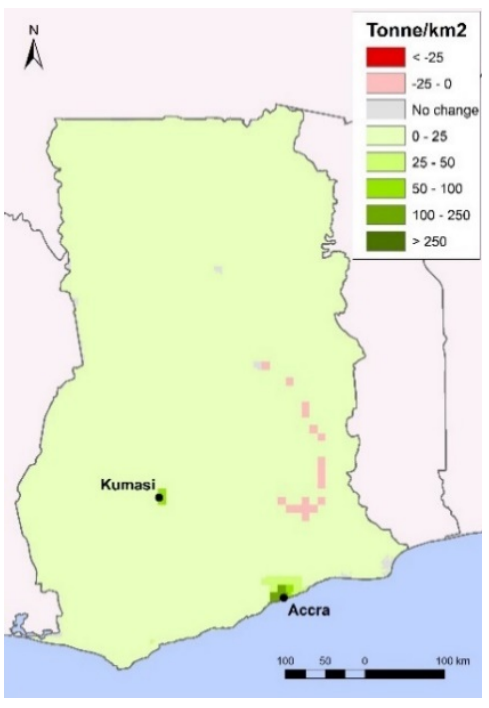

Change 2010-2030

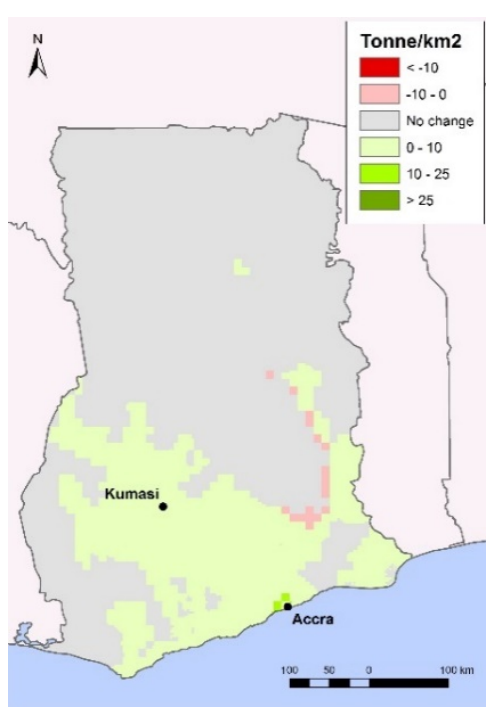

Change 2010-2050

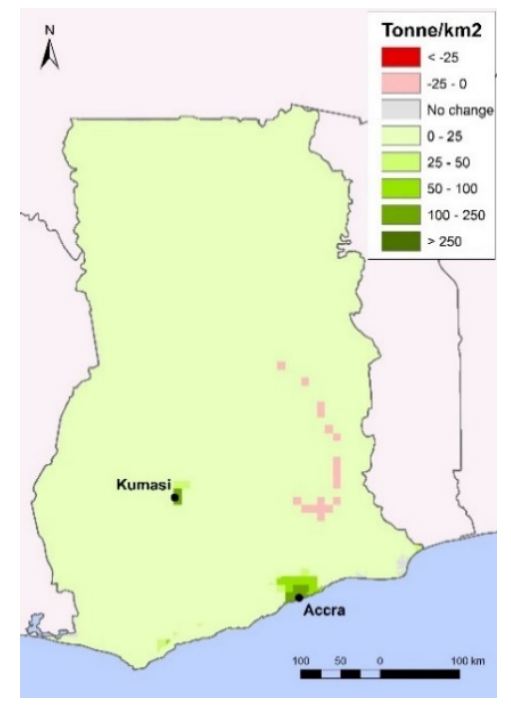

Change 2010-2050

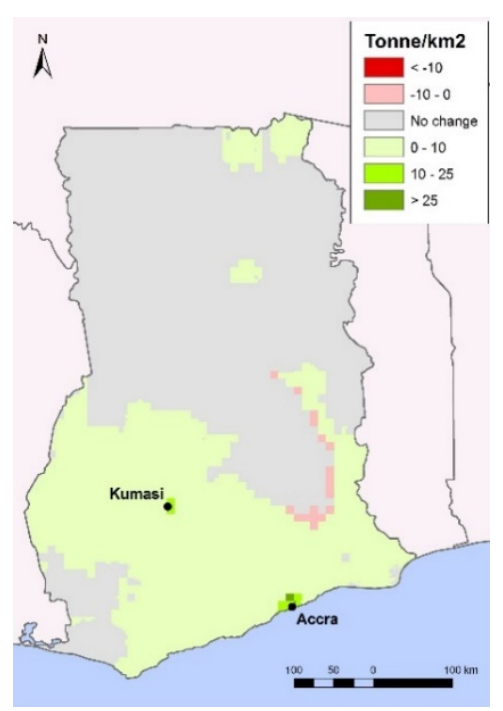

Figure 11 Changes in the consumption of vegetables and fruit, and rice in 2030 and 2050 for the SSP2 scenario

\subsubsection{Supply and demand compared}

As an illustration of mapping production and consumption in the areas of Ghana, we compare the supply and demand for rice for all grid cells in 2030 under the ECO scenario ${ }^{1}$. In particular, we compare supply and demand on an annual basis. Demand at grid cell level is measured in hectares as we calculate the area required to fulfil demand having been given a per capita consumption in 2030 in the ECO scenario. We can explore whether an area is rice exporting or rice importing. On the one hand, we know the area of rice production and the rice yield per hectare in 2030 for the ECO scenario. On the other hand, we know the population and the consumption per capita in 2030 for the ECO scenario. Based on the total rice production per grid cell and the total demand per grid cell, we can distinguish five different situations (see Figure 19).

\footnotetext{
1 Other results for different years, scenarios and approaches can be found at www.wur.eu/tssghana.
} 


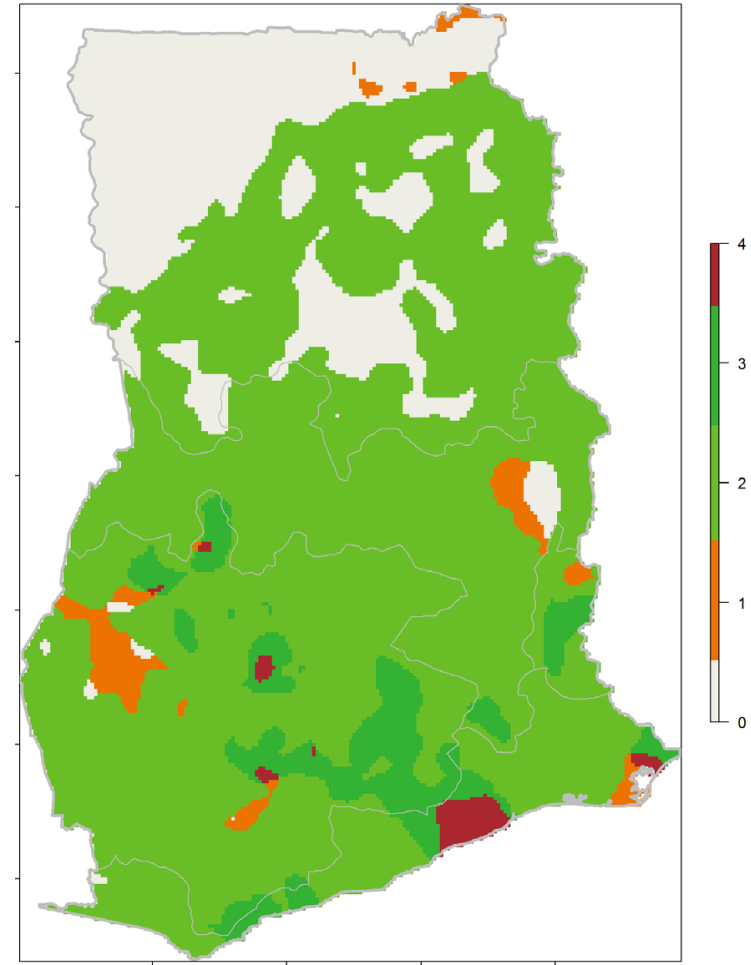

4: Red; import due to high demand

3: Dark green; export with high demand ( $>1.5 \mathrm{ha}$ )

2: Light green; export with demand less than 1.5 ha

1: Orange; import from other areas (demand<supply)

0 : Light grey; irrelevant because demand and supply are less than 1.5 ha

Figure 19 Demand and supply of rice comparison at grid cell level in 2030 for the ECO scenario

The red areas have a high rice demand and are rice-importing areas. These areas are the typical urban areas. The dark green areas are the areas with high rice demand but even higher rice production. These are rice-exporting areas. The light green areas have low rice demand but higher rice production, which is exported. Then, the orange areas have low rice demand and even lower rice production (rice-importing areas). The light grey areas have either no demand or no supply/production.

\subsubsection{Virtual production regions for urban consumption}

\section{Supply for a fixed area of demand}

Our main research question is how urban consumption of vegetables and fruit as well as rice will develop under different scenarios and how self-supporting Ghana can remain with respect to the production of these commodities. To explore this question, we produce virtual production maps which are maps that identify the required land to produce crops in order to fulfil the urban demand for a commodity. The productivity of the land is given, i.e. input for the MAGNET model and the productivity differs across scenarios (see Table 6 for vegetables and fruit, and Table 7 for rice). For the illustrations in this paragraph, the scenario ECO in the projected situation of 2030 is used.

We explored these virtual production areas for the urban area of Accra. We use an iterative procedure to search for sufficient production areas around Accra that will meet the demand for commodities in the Greater Accra area. Accra is located on the coast, so we take the coastline as the centre and we draw an imaginary circle around the centre. This is a circle with a $35 \mathrm{~km}$ radius which we identify as Greater Accra. Half of this circle is at sea so we only consider half of this circle which is land. The surface of this half circle representing the Greater Accra region is almost 60,000 hectares with 5.9 million inhabitants (see Figure 20). 


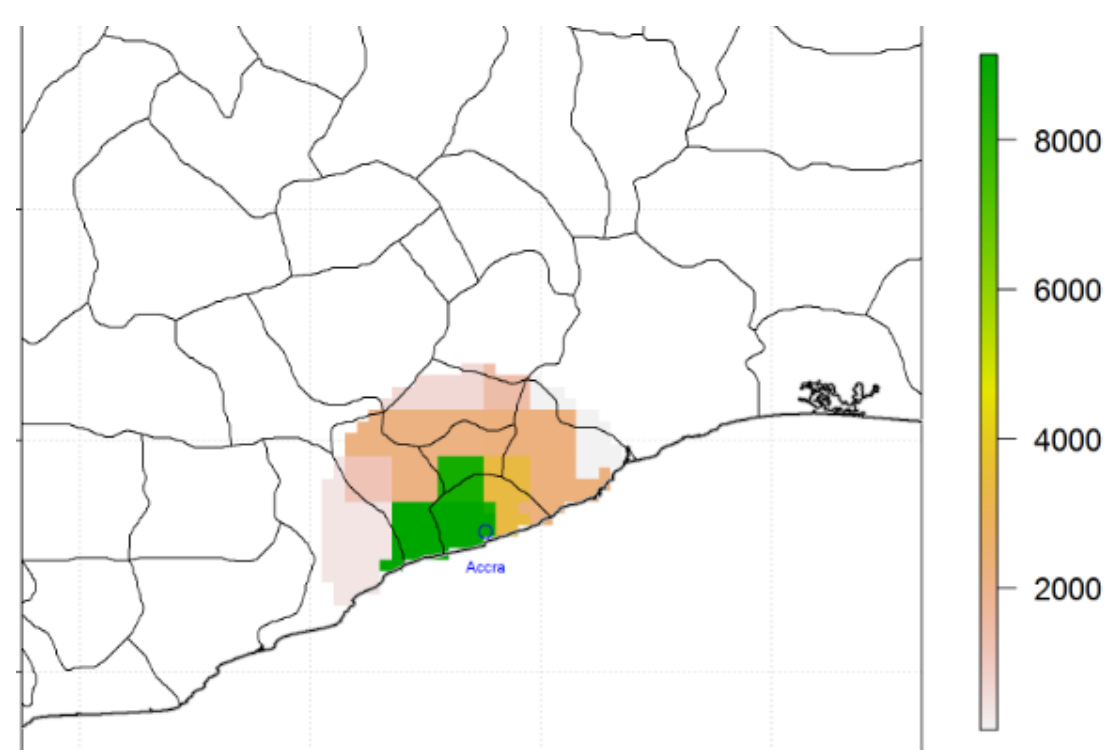

Figure 20 Population density (person per $\mathrm{km}^{2}$ ) for a fixed $35 \mathrm{~km}$ radius of Accra in 2030 under the ECO scenario

Given this population size and thus the demand, we explored the virtual production area for vegetables and fruit and for rice (see Figure 21). Both virtual production circles are much larger than the radius of $35 \mathrm{~km}$. For vegetables and fruit, the virtual production circles have a radius of $102 \mathrm{~km}$. In this circle, there are almost 60,000 hectares for vegetables and fruit production. In the case of rice, the virtual production circle has a radius of $202 \mathrm{~km}$ and there is little over 3,000 hectares available for rice production. Thus, the Greater Accra region is not self-supporting with vegetables and fruit, or rice.

The colours of the grid cells in Figure 21 indicate the number of hectares per grid cells for production of vegetables and fruit (left panel) and rice (right panel). If we compare vegetables and fruit production with rice production, we can conclude that there is less potential cropland for rice production. Both maps identify the hotspots for production. 


\section{Vegetables and fruit}

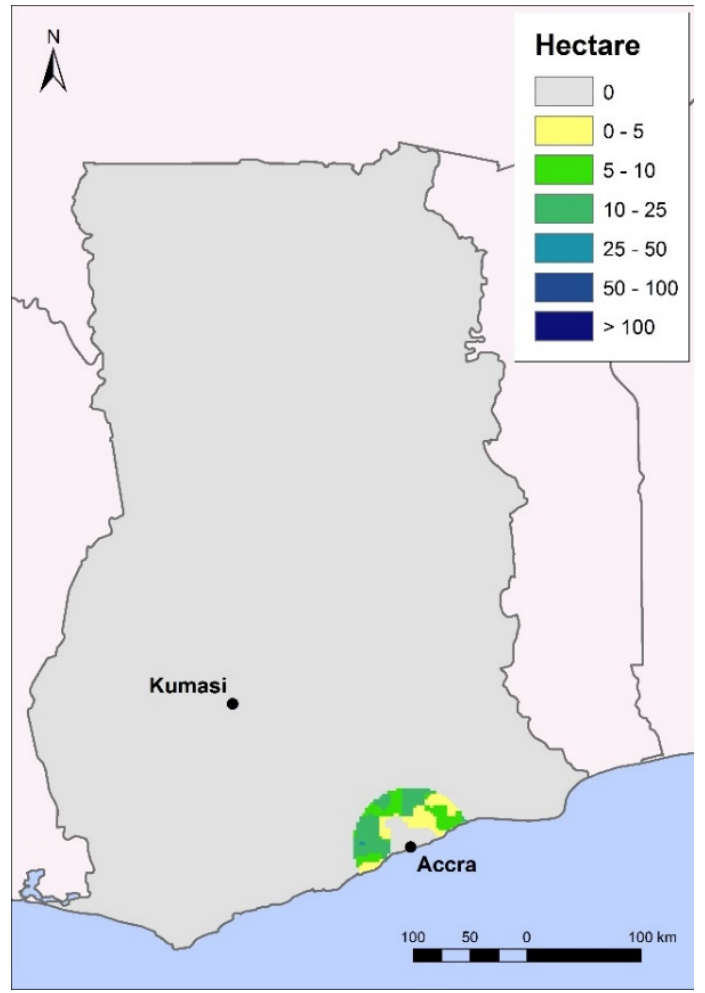

Radius $=102 \mathrm{~km} ;$ prod. area in radius $=$ 59,099 ha
Rice

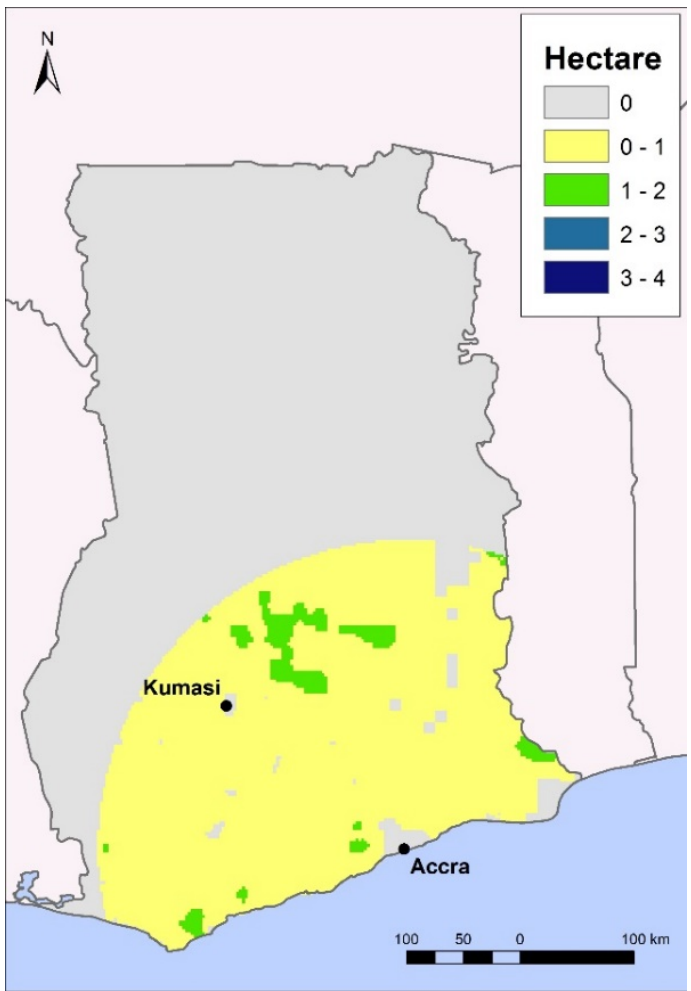

Radius $=202 \mathrm{~km} ;$ prod , area in radius $=3,080$ ha

Figure 12 Virtual production (ha per grid cell) of vegetables and fruit (left) and rice (right) in 2030 under the ECO scenario

Figure 21 shows that the virtual production circles for both vegetables and fruit, and rice are much larger than the circle of urban demand in the larger Accra region with a radius of $35 \mathrm{~km}$. However, in the area identified for production, there are also inhabitants that have a demand for vegetables and fruit as well as for rice. In Figure 21, these demands are ignored. In the next paragraph, we will explore virtual production maps in which we take into account the inhabitants or consumers in the virtual production areas.

\section{Supply equals demand for the virtual production circle}

As we now will take into account all inhabitants/consumers in the virtual production area, we use a different criterion for our iterative procedure to establish virtual production circles. We search for the break-even radius of an urban centre for which supply equals demand. We start with an urban centre and its demand for a food crop. We assume that the production of this food crop can be done on the crops lands available as close as possible to the urban centre. Whenever the production radius is extended, the demand for the food crop increases due to an increase in demand through an increase in the population from the areas added, and the production increases due to the production areas in the grid cell added. This procedure is continued until the supply of the food crop is equal to its demand. Furthermore, we explored this procedure for the Greater Accra region and additionally for Kumasi, because we want to check whether or not the virtual production areas of both Accra and Kumasi might overlap. We explored the virtual production circles for the food crops vegetables and fruit, and rice. Note that we identify cropland that is suitable for either growing vegetables and fruit or growing rice but not both.

The maps at the right of Figure 22 show the virtual production circles for vegetables and fruit for Accra and Kumasi, while the maps on the left show the population densities of the areas of Accra and Kumasi, which indicate the demand for fruit and vegetables. The break-even radius of the virtual vegetables and fruit production area for Accra is $170 \mathrm{~km}$. Within this virtual circle consumption equals production for vegetables and fruit. The total area of the virtual consumption/production circle is just 
over 153,000 hectares with 16.1 million inhabitants. The break-even radius of the virtual production area for Kumasi would be $40 \mathrm{~km}$, with a total surface of around 22,500 hectares and 2.87 million inhabitants. However, we can see that Kumasi is rather close to the production circle of Accra. Note that we do not take into account whether or not other urban areas are close to the vegetables and fruit production circle of other urban areas. We did consider differences in per capita consumption in Accra and Kumasi. According to the MAGNET results, the per capita consumption in the Greater Accra area is larger than in the Kumasi (forest) area.

Accra

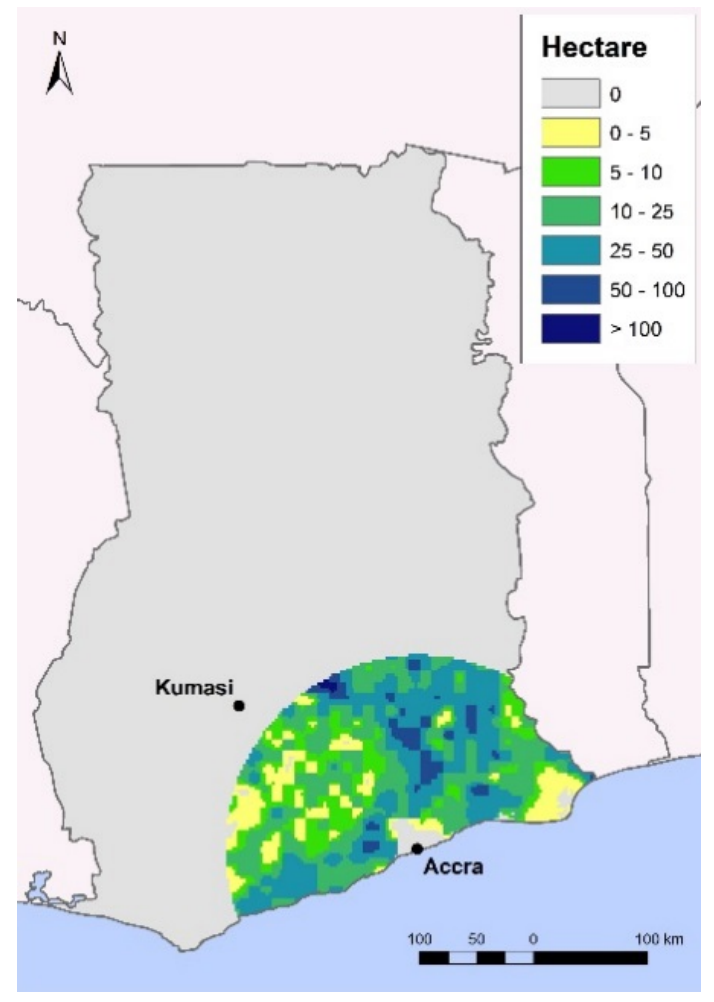

Kumasi

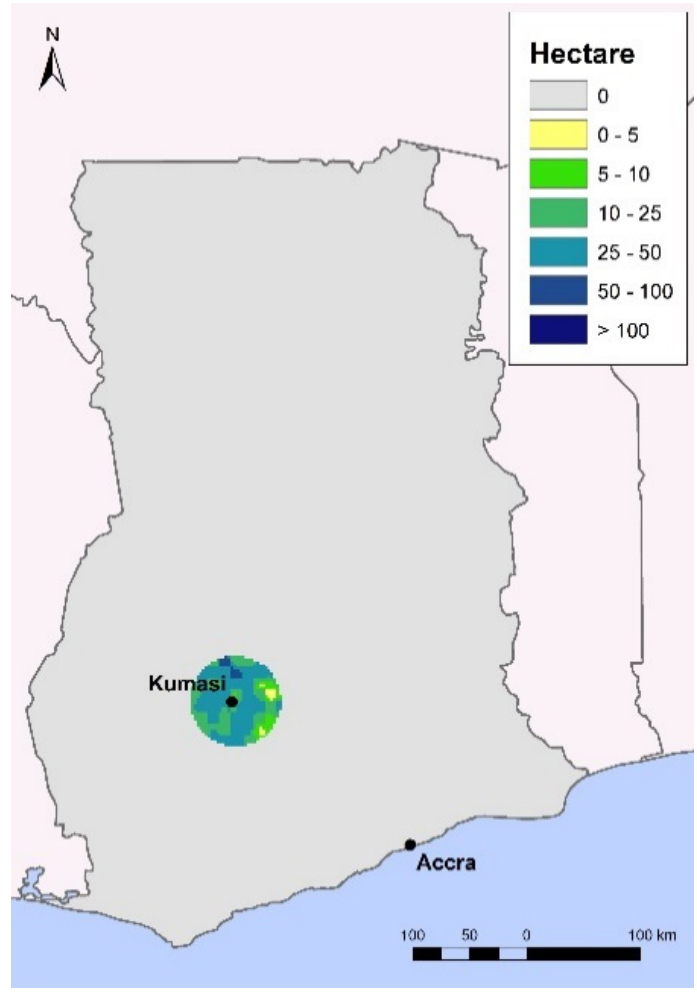

Figure 13 The area of virtual vegetable and fruit production for the urban centres of Accra and Kumasi in 2030 under the ECO scenario

Figure 23 presents the results for rice. The virtual production areas of rice for both Accra and Kumasi become circles. The radius of the virtual rice production circle for Accra is $520 \mathrm{~km}$, while the radius for Kumasi is $320 \mathrm{~km}$. The virtual production area of rice for Accra amounts to just over 13,000 hectares for 32.2 million inhabitants. For Kumasi, the virtual production area would be nearly 11,000 hectares for almost 31 million inhabitants. The virtual rice production areas are large because the potential cropland to grow rice is much smaller than for vegetables and fruit, for instance.

From the maps in Figure 23 we can see that the virtual production areas of rice for Accra and Kumasi largely overlap. This means that the Accra region is in the virtual circle of Kumasi and vice versa. The reason why the virtual circle of Accra has a larger radius is due to the location of Accra on the coast. 


\section{Accra}

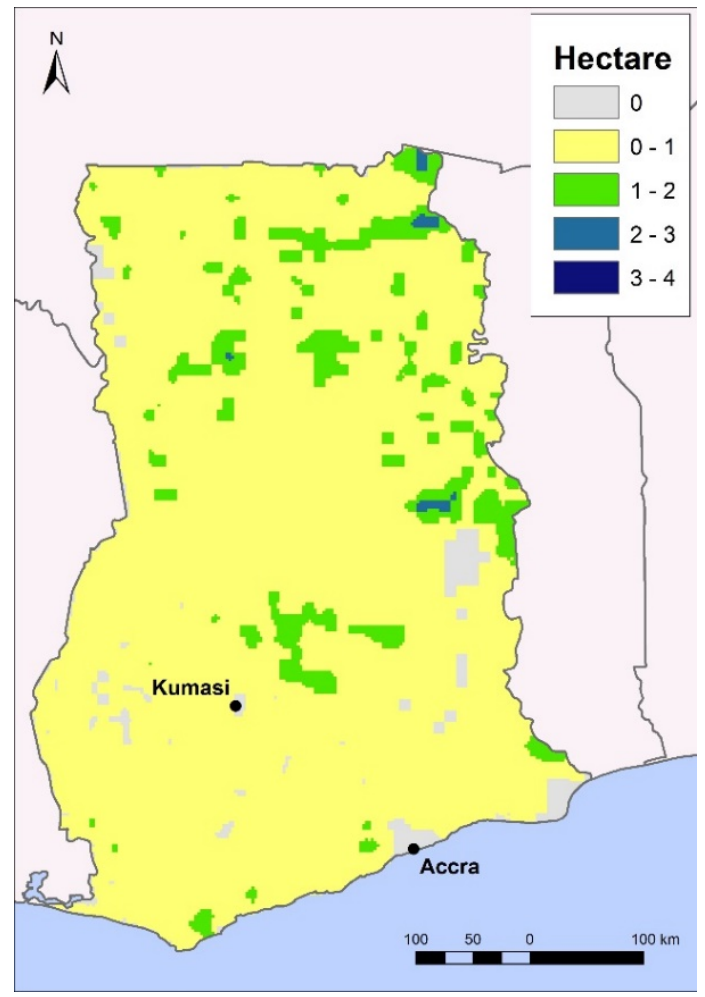

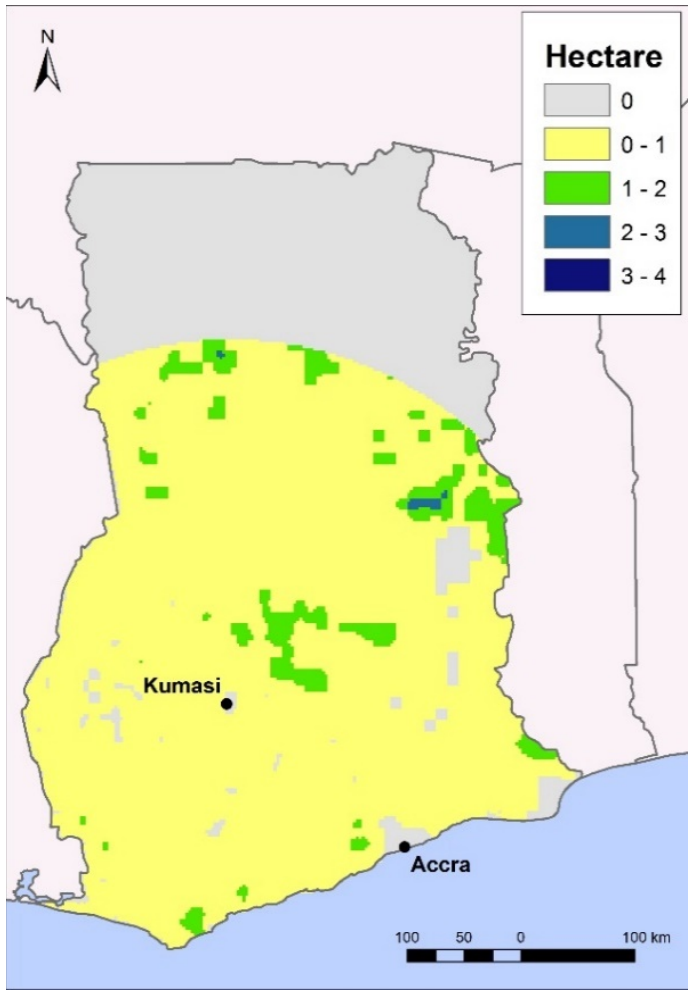

Figure 143 The area of virtual rice production for the urban centres of Accra (left) and Kumasi (right) in 2030 under the ECO scenario

Supply equals demand for the virtual production circle for Accra and Kumasi combined In addition to the illustration of the virtual production areas with the break-even principle of supply and demand for both Accra and Kumasi, we now take into account the possible overlap of the virtual production circles. In the case of rice, this is not a very interesting exercise, because the virtual production maps of rice already largely overlap (see Figure 23). For vegetables and fruit, however, the interactive search for virtual production for the combination of Accra and Kumasi might lead to changes in the maps. Green-coloured areas have approximately 100 hectares of land for vegetables and fruit production.

The right side of Figure 24 shows the virtual production of vegetables and fruit for the two urban centres combined. In this case it becomes rather difficult to identify the radius of the circle. However, we can look at the total area used for vegetables and fruit production. In the case of the two urban centres, the total land area for vegetables and fruit production was 184,000 hectares, which is larger than the sum of land areas for the separate virtual production circles in Figure 24, which was 175,000 hectares. 
Consumption of vegetables and fruit (persons per $\mathrm{km}^{2}$ )

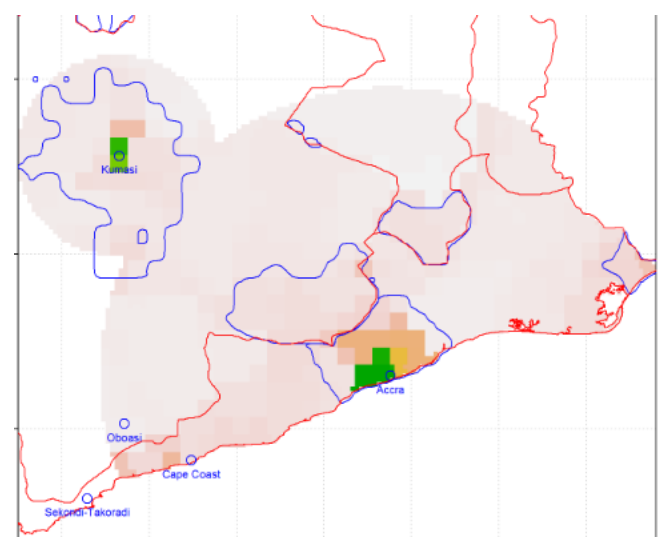

Virtual vegetables and fruit production circle (ha per grid cell)

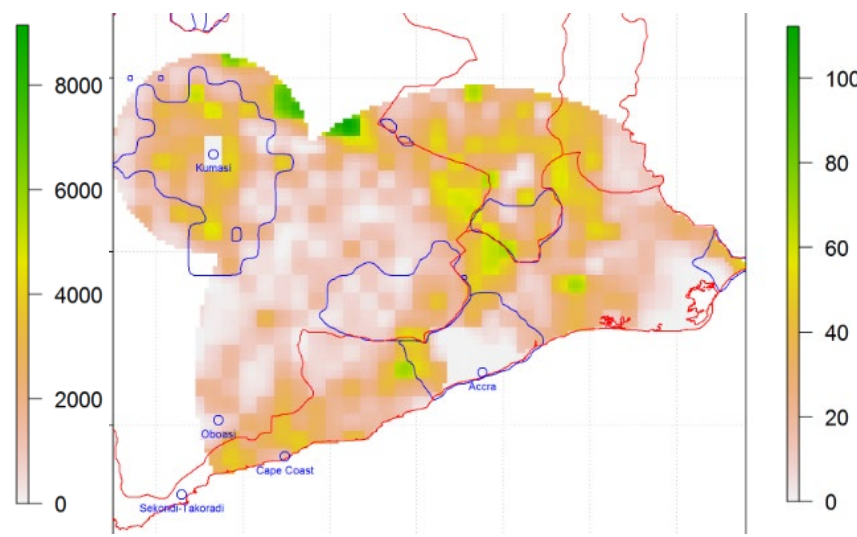

Figure 24 The area of virtual vegetables and fruit consumption (left) and virtual rice production (right) for the urban centres of Accra and Kumasi combined in 2030 under the ECO scenario 


\section{$5 \quad$ Discussion and conclusions}

\section{$5.1 \quad$ Discussion}

Food security is very much dependent on the wealth or income status of a person or their household. The macroeconomic projections determined with the MAGNET model do distinguish household cluster, but these clusters are too broad to analyse food security projections at a community, household or individual level. Within the MAGNET model, the household clusters could be based upon alternative criteria in which wealth status or income classes would be an important factor to consider. The exploration in this study was based on production and consumption in monetary terms. MAGNET results can also make a distinction and provide information on volume and price.

In this study, vegetables and fruit were used as an illustration of preparing virtual production circle maps. When all major crops are considered, it would be possible to perform allocation calculations and what the impact of competing crops would be (local utility). Information on restricting factors in the Global-Detector analyses (e.g. not enough production area for a crop) could be used as feedback to the MAGNET model input. In this way, both Global-Detector and MAGNET would benefit from the interaction between the approaches.

In this study, climate change was not taken into account. Climate change could increase the occurrence of extreme weather events and could affect the productivity of crops. With MAGNET, the impacts of SSP scenarios were already explored but additionally MAGNET could project the combinations of SSP and different RCP (i.e. climate scenarios) scenarios as well. Global-Detector can identify areas at risk (e.g. areas where the climate suitability for the crop deviates from optimum due to temperature increase or rainfall decrease), or areas that could benefit from climate change (towards optimum suitability).

The macroeconomic projections obtained with MAGNET are, to some extent, not fully in line with the expected developments of population growth in Ghana. In particular, the assumption that the distribution of the different urban and rural household clusters remains constant over time is inconsistent with the expected increase in urban population. This was partly addressed by the use of GIS downscaling tools, which allowed a differentiation between the developments in urban and rural population growth on a more refined scale, and as result, also the consumption levels in cities and rural areas. Nevertheless, since the share of urban population has been underestimated, so may have been the overall consumption projections at the country level, as urban population is associated with higher consumption levels per capita. Hence, forthcoming macroeconomic projections with MAGNET should strive to explicitly take into account developments on the country demographics. Yet, even when these assumption inconsistencies are addressed, large uncertainties will remain associated with future projection on food consumption and production. Therefore, these results should not be interpreted as accurate estimates, but instead be regarded as plausible projections of the order of magnitude of the changes in food consumption and production resulting from alternative developments in population growth and income per capita. Despite these limitations, the proposed approach is deemed valuable when implemented in decision support systems for analysis of urban food security issues, as it provides an overview of the most predominant trends and allows a differentiation between the developments in particular regions of the country according to their specific demographic, socio-economic and biophysical conditions. 


\subsection{Conclusions}

The TSS approach integrates decision support tools and stakeholder analyses for complex issues such as ensuring urban food security (UFS). This report demonstrated the application of the approach component related to the development of decision support tools to produce results that can be used as an input for discussion on future UFS in Ghana and the issue of self-support in the case of food supply to meet food demand in Accra and Kumasi. The use of Global-Detector and its maps illustrated a rather quick way to downscale data and projections from MAGNET and perform spatial analysis without the burden of acquiring additional data. Downscaling of macroeconomic results of future projections provides insights in future UFS. Given these insights, stakeholders might urge new policy or interventions. The results of the exercise are largely determined by the availability of data and maps. In particular, the more detailed information is available, the more accurate the results of our exercise will be. 


\section{References and websites}

Atkinson, Sarah J. 1995. "Approaches and Actors in Urban Food Security in Developing Countries." Habitat International 19 (2): 151-63. https://doi.org/10.1016/0197-3975(94)00063-8.

Birhane, Tesfay, Solomon Shiferaw, Seifu Hagos, and Katia Sarla Mohindra. 2014. "Urban Food Insecurity in the Context of High Food Prices: A Community Based Cross Sectional Study in Addis Ababa, Ethiopia." BMC Public Health 14 (1). https://doi.org/10.1186/1471-2458-14-680.

Codjoe, Samuel Nii Ardey, David Okutu, and Mumuni Abu. 2016. "Urban Household Characteristics and Dietary Diversity: An Analysis of Food Security in Accra, Ghana." Food and Nutrition Bulletin 37 (2): 202-18. https://doi.org/10.1177/0379572116631882.

Dijkshoorn-Dekker, M.W.C., M.J. Bogaardt, N.B.P Polman, and K. Soma. 2017. "Transition Support for Food Secure Metropolitan Regions." The Hague, The Netherlands: Wageningen Economic Research.

Dijkshoorn-Dekker, M.W.C., N.B.P Polman, M.J. Bogaardt, K. Soma, and A. Daane. 2017. "Inclusive Metropolitan Transitions; Challenges and Opportunities for Food and Green." The Hague, The Netherlands.

Garrett, James L., and Marie T. Ruel. 1999. "Are Determinants of Rural and Urban Food Security and Nutritional Status Different? Some Insights from Mozambique." World Development 27 (11): 1955-75. https://doi.org/10.1016/S0305-750X(99)00091-1.

Headey, Derek D., and William J. Martin. 2016. "The Impact of Food Prices on Poverty and Food Security." Annual Review of Resource Economics 8 (1): 329-51. https://doi.org/10.1146/annurevresource-100815-095303.

Hennen, Wil, Arjen Daane, and Kees Duijvendijk. 2017. "Global-Detector; GIS- and Knowledge-Based Tool for a Global Detection of the Potential for Production, Supply and Demand." In: Porto (Portugal).

Hertel, Thomas W., ed. 1997. Global Trade Analysis: Modeling and Applications. Cambridge University Press.

---. 2016. "Food Security under Climate Change." Nature Climate Change 6 (1): 10-13. https://doi.org/10.1038/nclimate2834.

Ingram, John. 2011. "A Food Systems Approach to Researching Food Security and Its Interactions with Global Environmental Change." Food Security 3 (4): 417-31. https://doi.org/10.1007/s12571-011-0149-9.

Kuiper, Marijke, Lindsay Shutes, and Diti Oudendag. 2017. "With Food and Nutrition Security Hinging on Inequality, Labour Allocation beyond Agriculture Proves a Neglected Key Driver in Long Term FNS Projections."

Kuiper, M.H., and L.J. Shutes. 2014. "Expanding the Household Coverage of Global Simulation Models: An Application to Ghana." The Hague: LEI Wageningen UR.

Linderhof, Vincent, Ricardo Vlijm, Vasco Pinto, Ireen Raaijmakers, and Marijke Dijkshoorn-Dekker, 2019. "Urban Food Security in Ghana: A Policy Review." The Hague, The Netherlands: Wageningen Economic Research.

Maxwell, Daniel G., ed. 2000. Urban Livelihoods and Food and Nutrition Security in Greater Accra, Ghana. Research Report 112. Washington, D.C: International Food Policy Research Institute.

Narayanan, Badri, Angel Aguiar, and Robert McDougall, eds. 2015. "Global Trade, Assistance, and Production: The GTAP 9 Data Base." Center for Global Trade Analysis. http://www.gtap.agecon.purdue.edu/databases/v9/v9_doco.asp.

Riahi, Keywan, Detlef P. van Vuuren, Elmar Kriegler, Jae Edmonds, Brian C. O’Neill, Shinichiro Fujimori, Nico Bauer, et al. 2017. "The Shared Socioeconomic Pathways and Their Energy, Land Use, and Greenhouse Gas Emissions Implications: An Overview." Global Environmental Change 42 (January): 153-68. https://doi.org/10.1016/j.gloenvcha.2016.05.009.

Shutes, Lindsay, Monika Verma, and Marijke Kuiper. 2015. "Changing Diets in a Changing World: Assessing the Impact of Urbanisation on Agriculture." The Hague, The Netherlands: Wageningen Economic Research. 
Swinnen, Johan. 2010. "The Right Price of Food: Reflections on the Political Economy of Policy Analysis and Communication." LICOS Discussion Paper. LICOS - Centre for Institutions and Economic Performance, KU Leuven. http://econpapers.repec.org/paper/liclicosd/25910.htm.

United Nations. 2015. "World Urbanization Prospects: The 2014 Revision." (ST/ESA/SER.A/366. United Nations, Department of Economic and Social Affairs, Population Division. https://esa.un.org/unpd/wup/Publications/Files/WUP2014-Report.pdf.

Van Dijk, Michiel, Maryia Mandryk, Marc Grambergen, David Laborde, Lindsay Shutes, Stehfest, Elke, Hugo Valin, and Katharina Zellmer. 2015. "Scenarios to Explore Global Food Security up to 2050: Development Process, Storylines and Quantification of Drivers." FOODSECURE Working paper D5.2.3.

Woltjer, Geert, Marijke Kuiper, Aikaterini Kavallar, Hans van Meijl, Jeff Powell, Martine Rutten, Lindsay Shutes, and Andrzej Tabeau. 2014. "The MAGNET Model: Module Description." LEI report 14-057. Wageningen: LEI - Wageningen UR. http://www.wageningenur.nl/nl/Publicatiedetails.htm?publicationId=publication-way-343535383037. 


\section{Appendix 1 Global-Detector}

\section{Background}

There is a growing trend towards internationalisation of the agri-food sector in order to find new markets and reduce costs. Entrepreneurs who want to expand their production or market possibilities abroad are often faced with inadequate and dispersed information about promising locations in the world. To assemble and harmonise all the relevant data for the best decisions may become very costly and time-consuming.

\section{Objective}

Our objective is to develop a generic tool for knowledge-based spatial analysis. A large set of indicators is readily available for use without any GIS processing. The model builder together with an expert can start instantaneously, so the result should be reached considerably faster and more efficiently compared to a customary approach where often tedious and time-consuming data tracing, collection and GIS processing have to take place before actual spatial analyses can start.

\section{Indicators of Global-Detector}

The raw data for most indicators of Global-Detector are downloaded open-source data from the Web with various formats: gridded GIS files (rasters), shapefiles and tabular csv. Using GIS procedures these are converted to more than 200 uniform $5^{\prime} \times 5^{\prime}$ indicators for climate, land use, infrastructure, geography, population density in various circles, country aspects (e.g. fragility, GDP), etc.

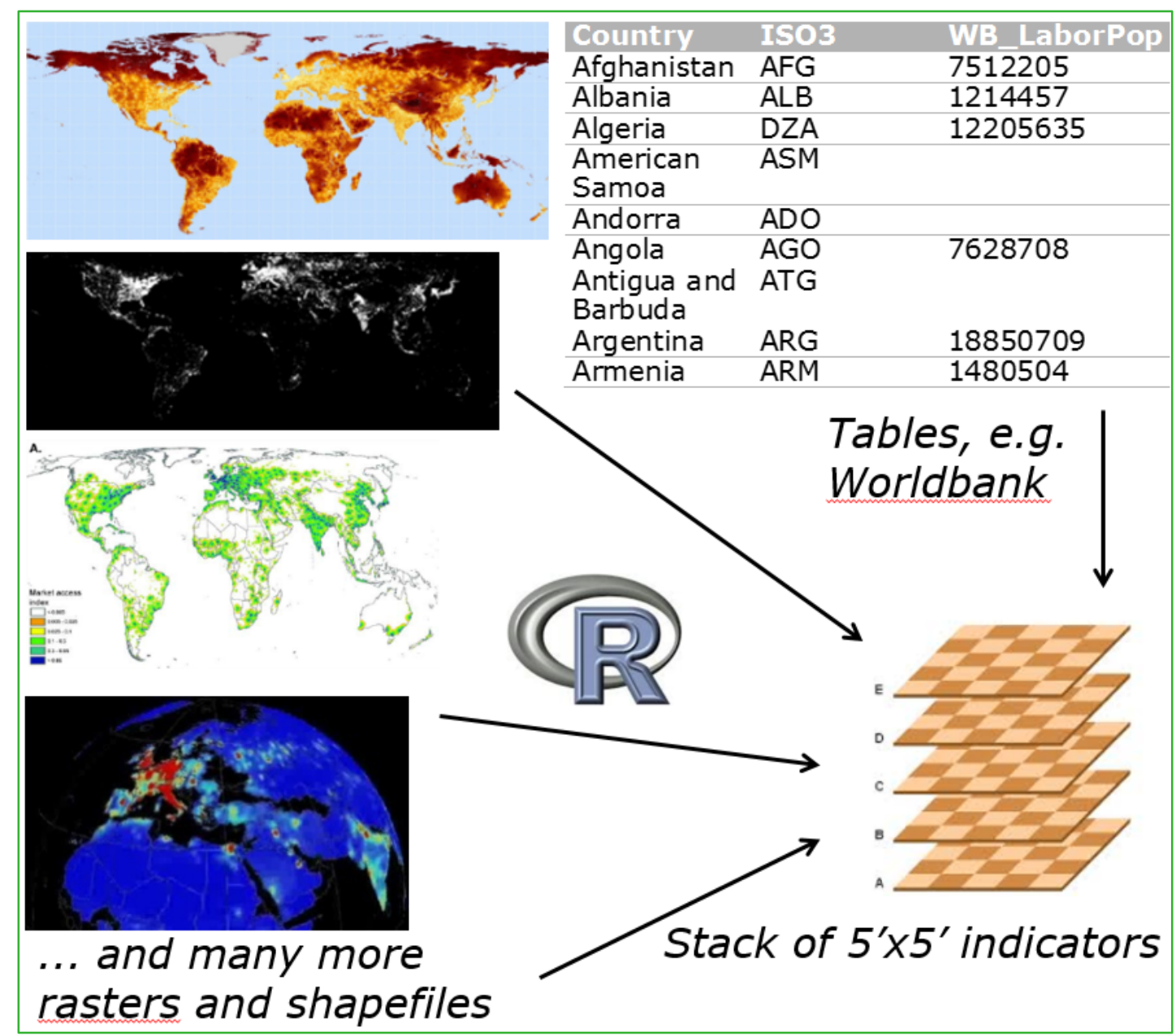

Figure A1 Creation of a stack of uniform $5^{\prime} \times 5^{\prime}$ indicators from downloaded freely available opensource data (GIS, tabular) 


\section{Role of the expert and knowledge engineer}

Figure A2 shows the process of creating a knowledge base and a map of production potential. Following these five steps, the first results can be achieved within a few hours. First, experts select relevant indicators (step 1) and express ways to transform and combine using maths functions (e.g. optimum) (step 2). In step 3, there is a meeting with other experts to discuss and validate intermediate and final maps. The knowledge engineer builds the mathematical model in close cooperation with the experts. In step 5, the maps with indicators are produced.

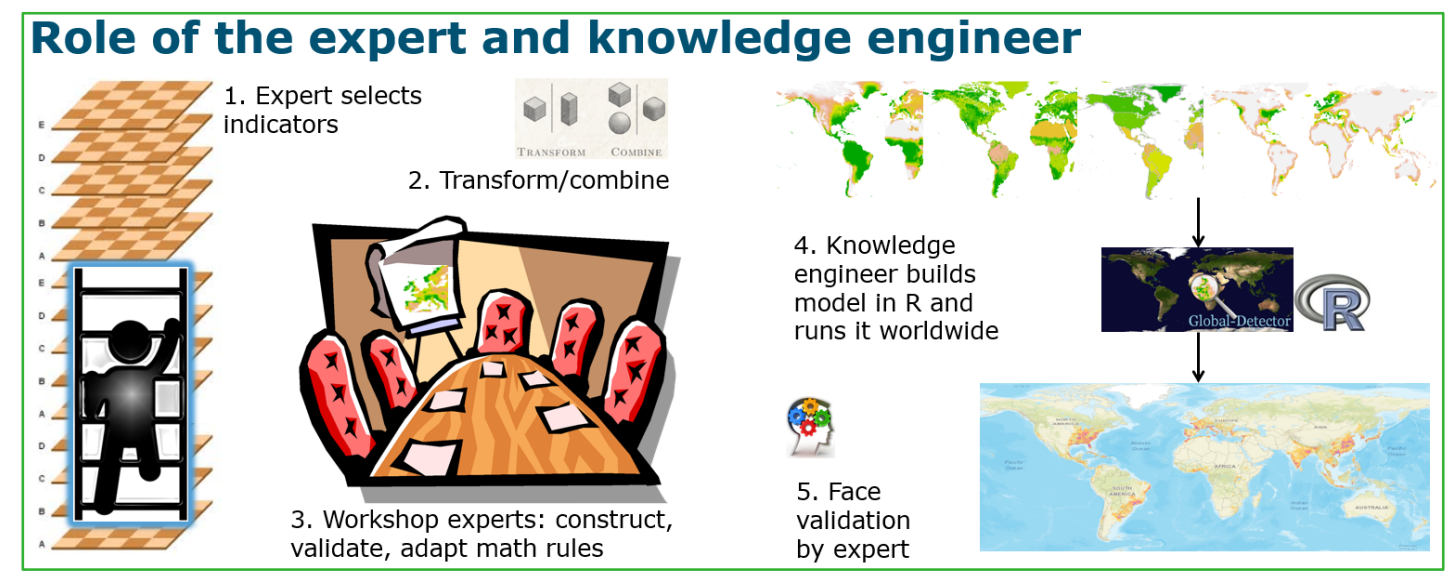

Figure A2 Process Global-Detector

\section{Case studies with Global-Detector}

The Global-Detector approach has been used in case studies already:

- Detection of the potential for production, e.g. tilapia in ponds, ornamental horticulture, pig production.

- Expected demand for a product, e.g. cherry tomatoes.

- Metropolitan assignments, e.g. urban food and recreation.

- Scenarios that have an effect on production/demand (e.g. floods).

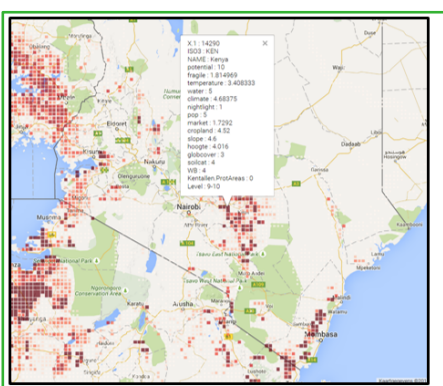

Potential for tilapia in Kenya and surrounding countries.

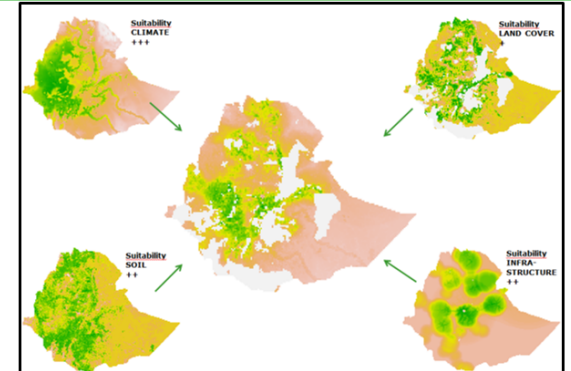

Potential for avocado production in Ethiopia based on four aspects.

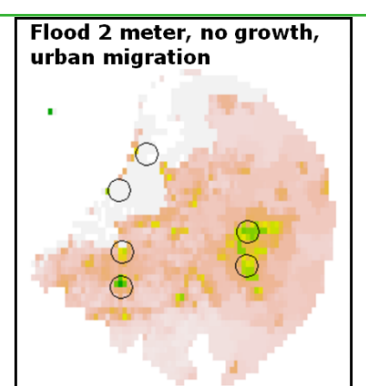

Scenario calculations with effects of floods on supply and demand of food.

Figure A3 Some illustrations of cases with Global-Detector

\section{Final result on world map (e.g. fruit and vegetables)}

The final result is a world map or several detailed maps of regions. For this 'fruit and vegetables' example, about 40 indicators of Global-Detector have been chosen and applied. In a workshop with eight experts, these indicators have been transformed (e.g. mean temperature to optimal temperature and combined). Results can be aggregated to country or province level. The data from a world map can be combined with Google Maps for a clear presentation: detail shows 'Potential for flowering and bedding plants in Ethiopia' 


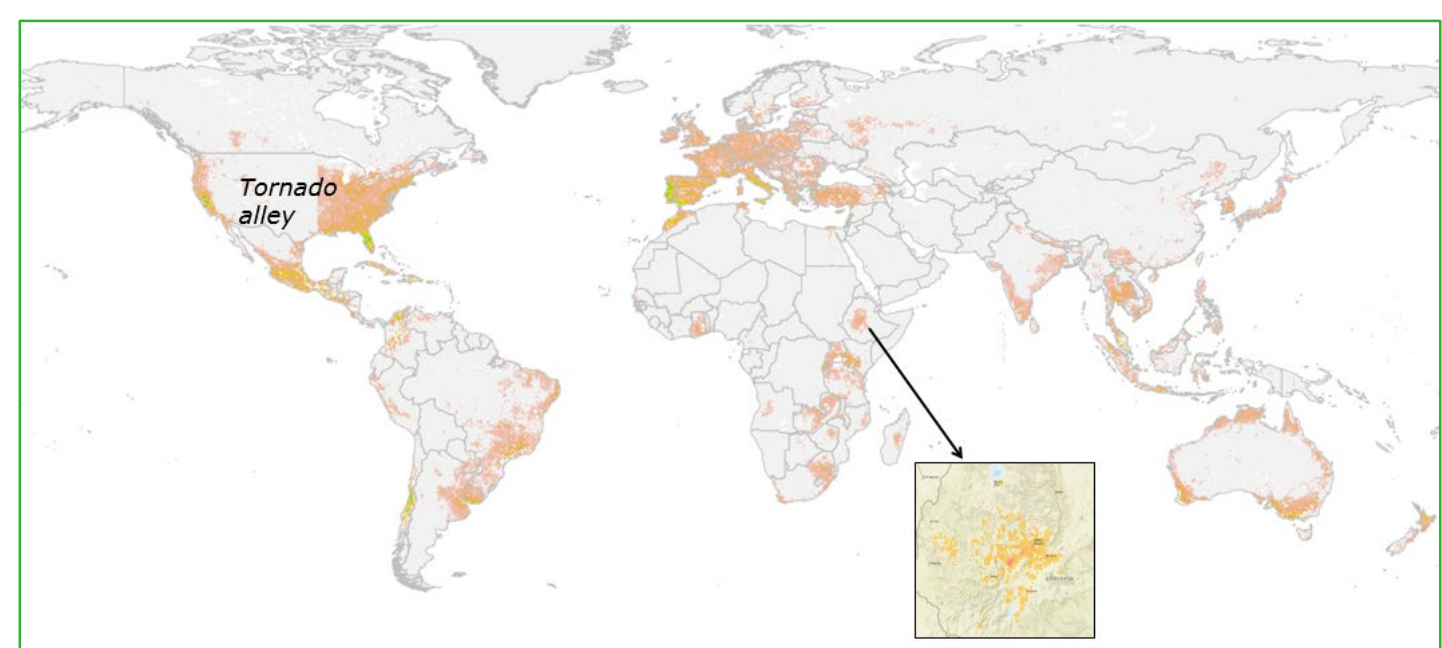

Figure A4 Final result of the case 'Potential for fruit and vegetables'

\section{Conclusions and future potential}

- Global-Detector is a generic tool for knowledge-based spatial analysis in a fast and straightforward way, applicable in various cases.

- The expert is crucial (selection, face validation, 'tacit knowledge').

- The instrument is helpful for entrepreneurs to gain information from target countries and to locate promising locations in the world.

- Global-Detector is valuable when applied in conjunction with existing models, e.g. with the general equilibrium tool MAGNET which covers the entire global economy. Global-Detector can be made to downscale results, and so increase the value of both models.

- There is an intention to make Global-Detector more dynamic and accessible with a Web-based presentation version.

- Possibilities for market demand can be augmented. 


\section{Appendix 2 Consumption of vegetables and fruit}

Table A1 Exports and imports of the commodity 'vegetables, fruit and nuts' as a share (\%) of total production value in Ghana

\begin{tabular}{|c|c|c|c|c|c|c|c|}
\hline & & \multicolumn{3}{|c|}{ Amounts (million USD) } & \multicolumn{3}{|c|}{ Share of production ( $\%)$} \\
\hline & & 2010 & 2030 & 2050 & 2010 & 2030 & 2050 \\
\hline \multirow[t]{3}{*}{ Production } & SSP2 & 6,939 & 12,991 & 17,690 & & & \\
\hline & ECO & 7,100 & 12,531 & 18,153 & & & \\
\hline & TLTL & 7,100 & 12,308 & 13,709 & & & \\
\hline \multirow[t]{3}{*}{ Exports } & SSP2 & 232 & 1,309 & 1,566 & 3.3 & 10.1 & 8.9 \\
\hline & ECO & 280 & 1,212 & 2,554 & 3.9 & 9.7 & 14.1 \\
\hline & TLTL & 280 & 1,190 & 764 & 3.9 & 9.7 & 5.6 \\
\hline \multirow[t]{3}{*}{ Imports } & SSP2 & 53 & 50 & 52 & 0.77 & 0.39 & 0.29 \\
\hline & ECO & 49 & 47 & 40 & 0.69 & 0.38 & 0.22 \\
\hline & TLTL & 49 & 40 & 47 & 0.69 & 0.33 & 0.34 \\
\hline
\end{tabular}

Source: MAGNET simulations (Kuiper et al. 2017) 


\section{Appendix 3 Consumption of paddy rice}

Table A2 Exports and imports of the commodity 'paddy rice' as a share (\%) of total production value in Ghana

\begin{tabular}{|c|c|c|c|c|c|c|c|}
\hline & & \multicolumn{3}{|c|}{ Amounts (million USD) } & \multicolumn{3}{|c|}{ Share of production $(\%)$} \\
\hline & & 2010 & 2030 & 2050 & 2010 & 2030 & 2050 \\
\hline \multirow[t]{3}{*}{ Production } & SSP2 & 401 & 1,022 & 1,477 & & & \\
\hline & ECO & 407 & 981 & 1,715 & & & \\
\hline & TLTL & 407 & 969 & 1,167 & & & \\
\hline \multirow[t]{3}{*}{ Exports } & SSP2 & 8 & 423 & 696 & 2.0 & 41.4 & 47.1 \\
\hline & ECO & 13 & 404 & 969 & 3.2 & 41.2 & 56.5 \\
\hline & TLTL & 13 & 396 & 471 & 3.2 & 40.9 & 40.4 \\
\hline \multirow[t]{3}{*}{ Imports } & SSP2 & 0.57 & 0.13 & 0.25 & 0.142 & 0.013 & 0.017 \\
\hline & ECO & 0.47 & 0.21 & 0.28 & 0.115 & 0.021 & 0.016 \\
\hline & TLTL & 0.47 & 0.19 & 0.47 & 0.115 & 0.020 & 0.040 \\
\hline
\end{tabular}

Source: MAGNET simulations (Kuiper et al. 2017) 
Wageningen Economic Research P.O. Box 29703

2502 LS The Hague

The Netherlands

$\mathrm{T}+31(0) 703358330$

E communications.ssg@wur.nl

www.wur.eu/economic-research

Wageningen Economic Research REPORT

2019-057a
The mission of Wageningen University \& Research is "To explore the potential of nature to improve the quality of life". Under the banner Wageningen University \& Research, Wageningen University and the specialised research institutes of the Wageningen Research Foundation have joined forces in contributing to finding solutions to important questions in the domain of healthy food and living environment. With its roughly 30 branches, 5,000 employees and 10,000 students, Wageningen University \& Research is one of the leading organisations in its domain. The unique Wageningen approach lies in its integrated approach to issues and the collaboration between different disciplines. 



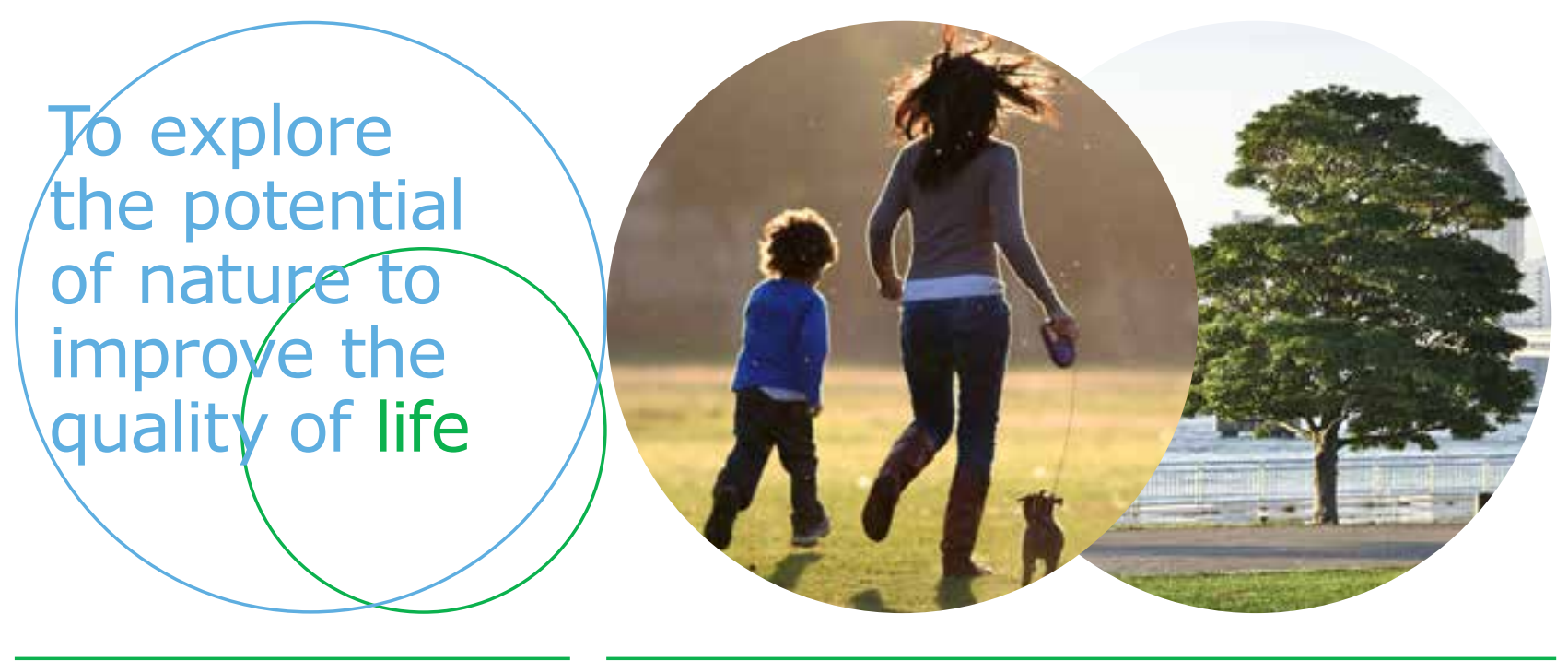

Wageningen Economic Research P.O. Box 29703

2502 LS Den Haag

The Netherlands

E communications.ssg@wur.nl

www.wur.eu/economic-research

Report 2019-057a

ISBN 978-94-6343-960-2
The mission of Wageningen University \& Research is "To explore the potential of nature to improve the quality of life". Under the banner Wageningen University \& Research, Wageningen University and the specialised research institutes of the Wageningen Research Foundation have joined forces in contributing to finding solutions to important questions in the domain of healthy food and living environment. With its roughly 30 branches, 5,000 employees and 10,000 students, Wageningen University \& Research is one of the leading organisations in its domain. The unique Wageningen approach lies in its integrated approach to issues and the collaboration between different disciplines. 